\title{
فعالية استخدام مسرح الطفل في تنمية السلوكيات الإيجابية لدي الأطفال المعاقين عقليا القابليز للتعلم
}

$$
\begin{aligned}
& \text { (إعراد } \\
& \text { الباحثة/ منى محمد أحمد روميه } \\
& \text { للحصول علي درجت الماجستير في التربيت } \\
& \text { (مناهج وطرق تعليم الطفل - فئات خاصتّ) }
\end{aligned}
$$$$
\text { إسرافـ }
$$

$$
\begin{aligned}
& \text { د/ قايزة أحمد عبد الرازق } \\
& \text { أ.د/ سحر توفيق نسيم } \\
& \text { مدرس بقسم العلوم الاساسيت } \\
& \text { أستاذ مناهـج وطرق تعليم الطفل } \\
& \text { كليت التربيت للطفولتمالمبكرة } \\
& \text { وعميد كليتت التوبيت للطفولتي } \\
& \text { جامعت المنصورة } \\
& \text { المبكرة ـ جامعت المنصورة }
\end{aligned}
$$

المجلت العلميت لكليت رياض الأطفالـ جامعت المنصورة

$$
\text { المجلد السادس ـ العدد الأول }
$$


فعالية استخدام مسرح الطفل في تنمية السلوكيات الإيجابية لدي الأطفال المعاقين عقليا القابلين للتعلم

أر منى محمد أحمد روميه

\section{مقدمة}

بدأت المجتمعات في عالمنا المعاصر بالعناية بالأطفال ذوى الاحتباجـات

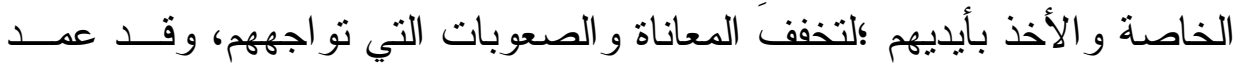

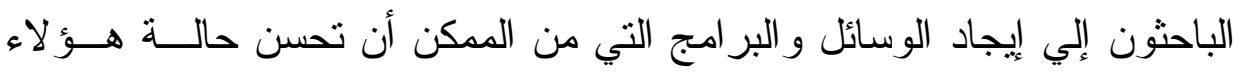

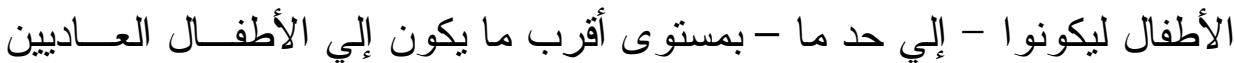

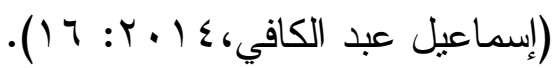

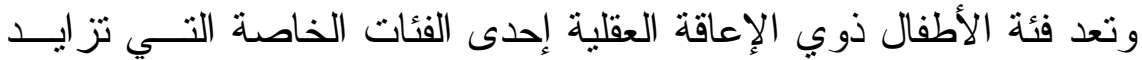

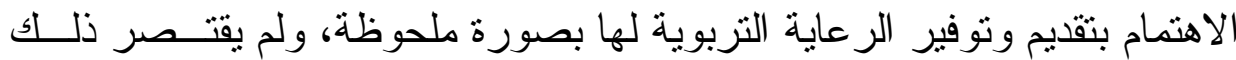

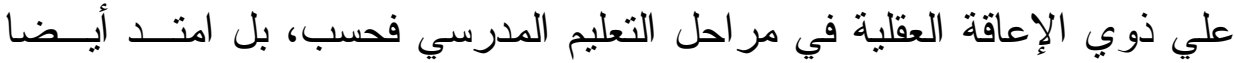

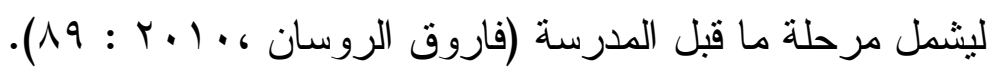

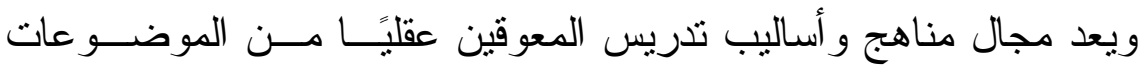

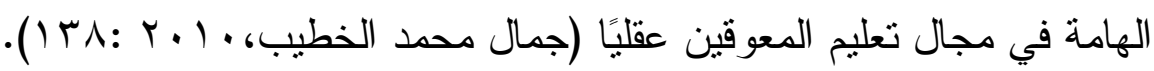
فالتدريس بواسطة مسرحة المنهج أسلوبا مميزاً حيث يحتاج الأطفال ذوي

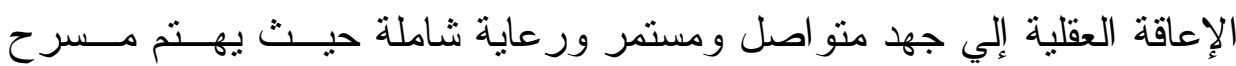

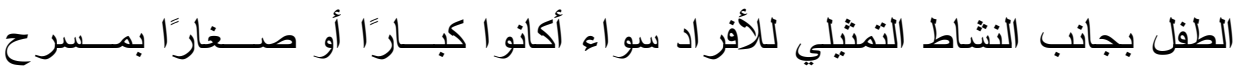

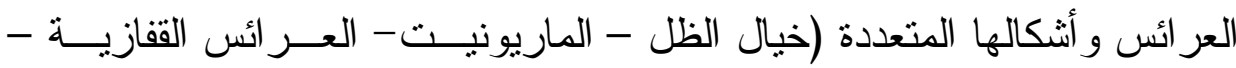
* للحصول علي درجتا الماجستير في التربيتة (مناهج وطرق تعليم الطفل - فئات خاصت). 
عر ائس القضبان ) بالإضـافة إلي المسرح الغنائي ، المسرح التعليمي ، الهـسرح

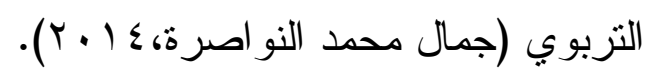

لذلك يتفق المدخل المسرحي مع طبيعة الاطفال المعاقين عقليًا لأنه يقوم

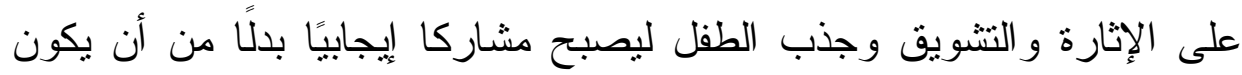
متلقًا سلبيًا ؛مما يساعد الطفل المعاق علي تعميق الفهم في ذهنه.

\section{مشكلة الار اسة}

تبلورت مشكلة الار اسة الحالية في الأسئلة التالية : • ما فعالية مسرح الطفل في تتمية السلوكيات الإيجابية لدى الأطفال المعاقين عقليًا القابلين للتعلم ؟ هابه

\section{أهداف الاراسة : أن}

ا. قياس فعالية مسرح الطفل في تتمية السلوكية الإيجابية لاى الأطفال المعاقين عقليًا القابلين للتعلم . r. التحقق من استمر ارية فعالية مسرح الطفل في تتمية العادات السلوكية

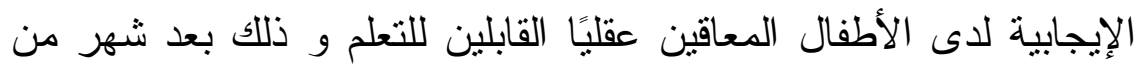
التطبيق (القياس التتبعي) . أهمية الار اسة : - أن

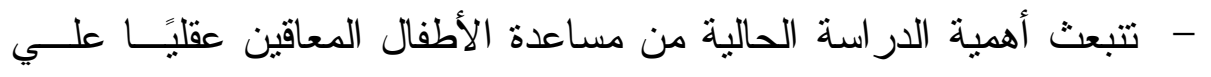

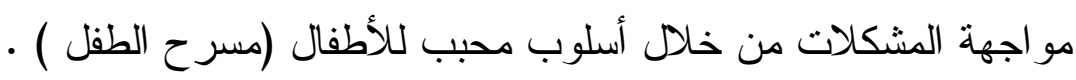

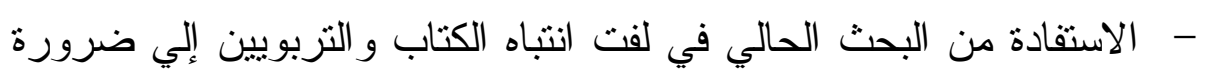
اعداد مسرحيات متخصصة لتعليم ذوى الاحتياجات الخاصة. 
المفاهيم الإجر ائية للار اسة :

فعالية

وتعرفها الباحثة إجرائيًا: مدي التأثير الإيجابي لمسرح الطفل في تتميــة

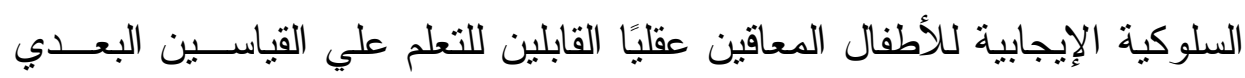

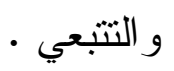

مسرح الطفل

وتعرفه الباحثة إجرائيًا: هو إحدى مداخل التعليم و التعلم التي تــتم فــي

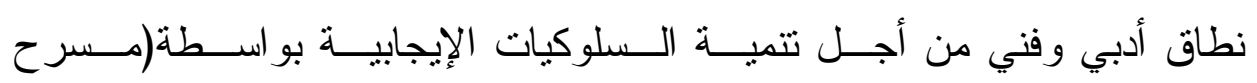
العر ائس)لاي أطفال المعاقين عقليًا . لمني

$$
\text { مسرح العرائس }
$$

وتعرفه الباحثة إجرائيًا: هو إحدى الوسائل التعليمية التي يستخدم فيهــا

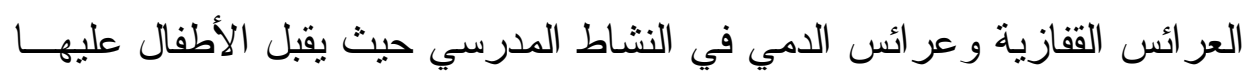

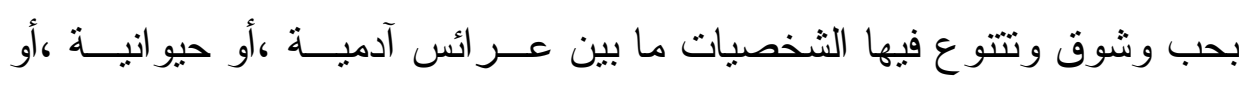
نباتية ، أو جماد لتتمية السلوكيات الإيجابية لدى الأطفال المعاقين عقليًا القـابلين للتعلم

المعاقين عقليا

وتعرفهم الباحثة إجر ائيا: هم الأطفال الذين لا تساعدهم قدر اتهم العقليـــة

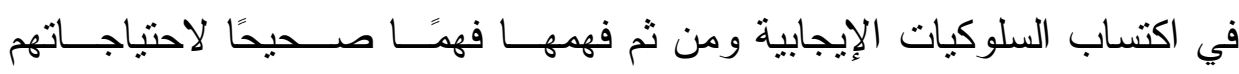

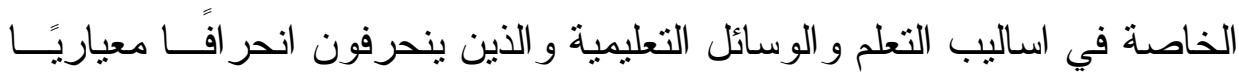
سالبًا عن المتوسط علي مقياس القدرة العقلية (بينيه) . 
السلوكيات الإيجابية

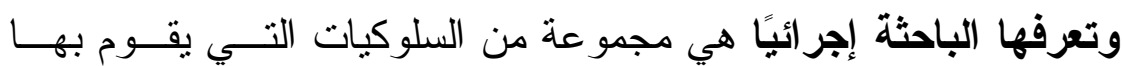

الأطفال المعاقين عقليًا القابلين للتعلم وفقا في إطار قو اعد منظمة للسلوك و التـي هني يتم تعزيزها من خلال ردود أفعال القائمين علي تعليمهم تربويًا داخـلـل البيئيــة فيـة

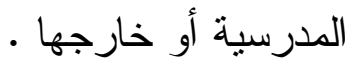

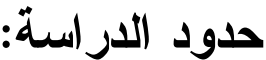

- الحد الزماني : استغرق تطبيق مسرح الطفل (^) أسابيع من الفصل

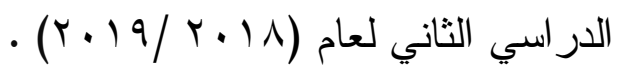

- الحد المكاني : تم تطبيق مسرح الطفل بمدرسة التزبية الفكرية التابعة

لإدارة أجا التعليمية بمحافظة الدقهلية.

- الحد البشرى: تتمثل عينة الدراسة في الأطفال المعاقين عقليًا القابلين

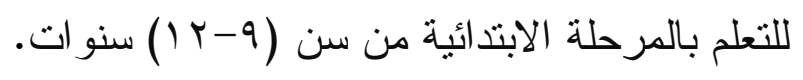

الإطار النظري و الار اسات السابقة:

الأطفال المعاقين عقليًا: تتعدد تعريفات المعاقين عقليًا فليس مسـن الـسهل

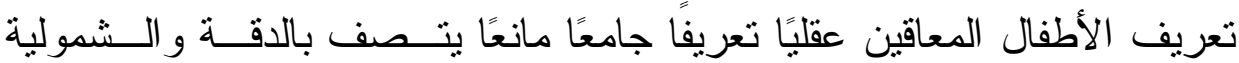

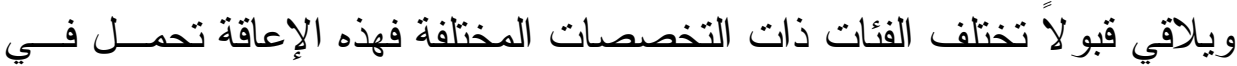

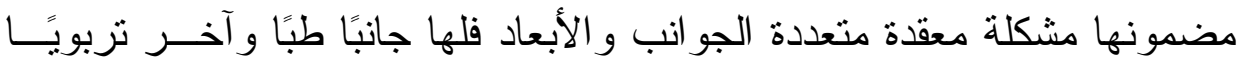

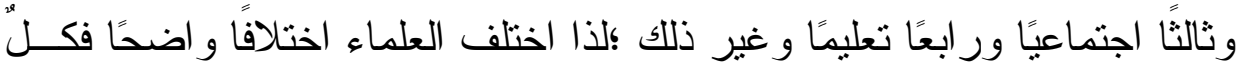
حسب التخصص العلمي الذى ينتمى إليه فكلاً منهم عرفها بحسب الجانب الــذي

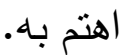

المجلد السادس




\section{1-الإعاقة العقلية من المنظور الاجتماعي}

تصنيف الأطفال المعاقين عقلياً بعد تطبيق مقاييس النضج الاجتماعي و السلوك التكيفي عليهم وذلك أربع فئات على أساس درجة كل فئة في مقياس

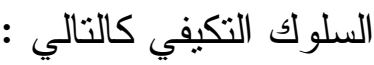

- فئة الإعاقة العقلية البسيطة وتتحصر نسبة التكيف للأطفال فيما بين

$$
\text { ( } v)-\lambda \varepsilon)
$$

- فئة الإعاقة العقلية المتوسطة وتتحصر نسبة التكيف للأطفال فيما بين

$$
(0 \wedge-v \cdot)
$$

- فئة الإعاقة العقلية الثديدة وتتحصر نسبة التكيف للأطفال فيما بين( -

$(\leq 0$

- فئة الإعاقة العقلية الحادة وتتحصر نسبة التكيف للأطفال فيما بين ؟؟

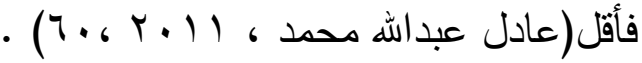

$$
\begin{aligned}
& \text { r- الإعاقة العقلية من المنظور السيكومترى }
\end{aligned}
$$

- - يقوم المنظور السيكومترى في تحديده لمفهوم الإعاقة العقلية علي استخدام

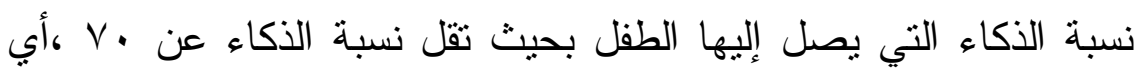
تقل عن المتوسط بمقدار انحر افين معاريين على الأقل، و هناك أربع فئات للإعاقة العقلية بناء على نسبة الذكاء كالتالي:- الإعاقة العقلية البسيطة Mild وتضم .10\% تقريبا من الأطفال

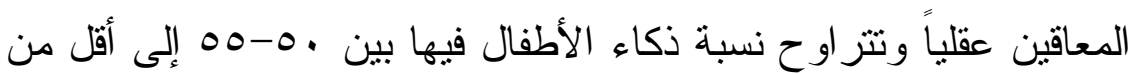

$$
\checkmark \text {. }
$$


- الإعاقة المتوسطة Moderate وتضم حوالى ·1\% ثقريباً من الأطفال

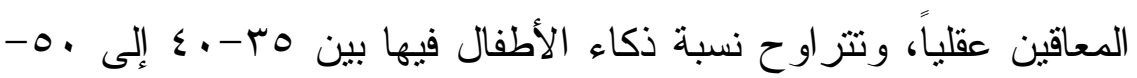
00

- الإعاقة العقلية الثديدة Severe وتضم حو الى r-ء٪ تقريباً من إجمالي

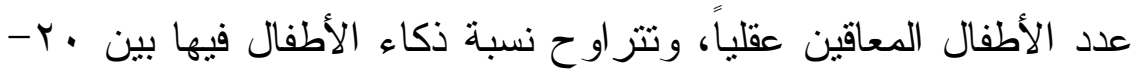

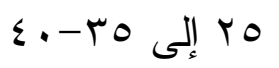

- الإعاقة العقلية الحادة أو الثديدة جداً Profound وتضم حوالي ر-r \% تقريباً من إجمالي الأطفال المعاقين عقلياً، وتكون نسبة ذكاء الأطفال فيها

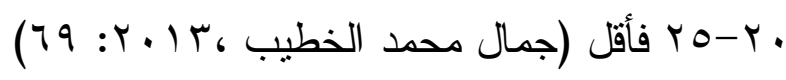
r- الإعاقة العقلية من المنظور التربوي تضم الإعاقة العقلية من هذا المنظور ثناث فئات وهي على النحو التالي:- القابلون للتعلم Educable وتكون لدى الطفل بعض القدرات الأكاديمية التي تساعده على التحصيل حتى مسنوى الصف الخامس فقط بحد أقصى، ويكون المتوسط هو الصف الثالث أو الرابع لُّنى

- القابلون للتدريب Trainable وتكون لدى الطفل قدرات أكاديمية أقل تؤهله حتى مستوى الصف الأول فقط بحد أقصى بينما يقل المنوسط عن ذللك، ويمكن تدريب الطفل على القيام ببعض المهن البسيطة - المعتمدون Custodial وهم أولئك الذي نقل نسبة ذكائهر عن OY،ويعتدون اعتماداً كلياً على غيرهم طو ال حياتهم (فاروق الروسان $(90: Y \cdot) V_{6}$ 
وقد تبنت الباحثة في هذه البحث تعريف الجمعيــة الأمريكيــة للإعاقــات

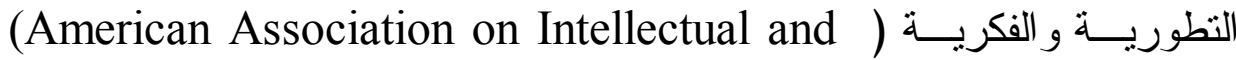

Developmental Disabilities, 2007 (AAIDD).

و ينص تعريف الجمعية الأمريكية على أن الإعاقة العقلية تـشير إلـي

قصور ملحوظ في الوظائف العقلية العامة، وفي الوظائف التكيفية حيث بظهـر

ذللك من خلال تدني مستوي المهار ات الإدر اكية و الاجتماعية و التكيفية، وتظهـر

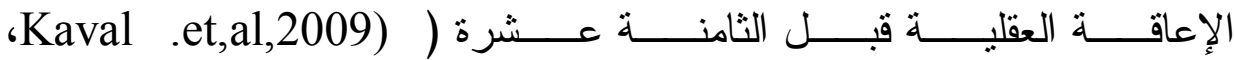

( (McDermott,Durkin\&Stein,2009,P3 خصائص الأطفال المعاقين عقلياً القابلين للتعلم

يتميز المعاقين عقليًا بالفروق الفردية فيما بينهم، لذلك فإنه يصعب تمييـز

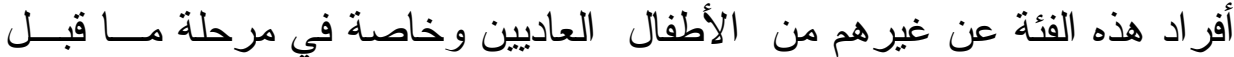

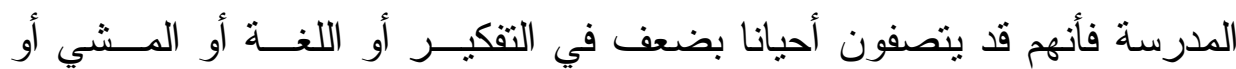

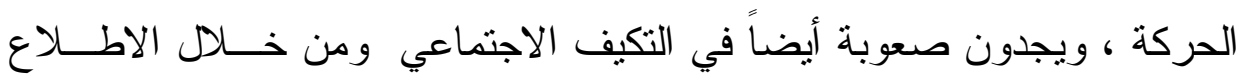

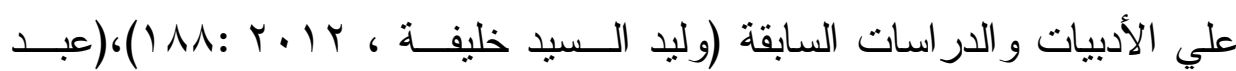

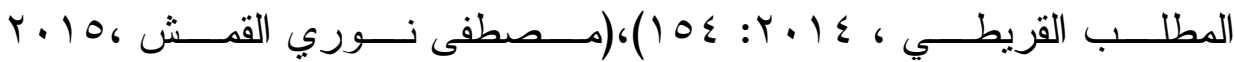

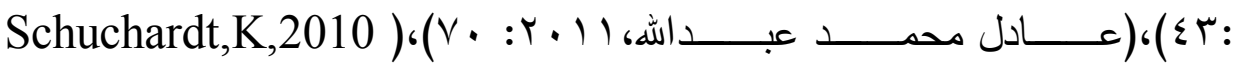
(Sideridis,2009)،( Tremblay , Karine N.et.al,2010)، وسنستخلص الباحثة أهم هذه الخصائص للمعاقين عقليًا القابلين للتعلم وهي كما يلي :

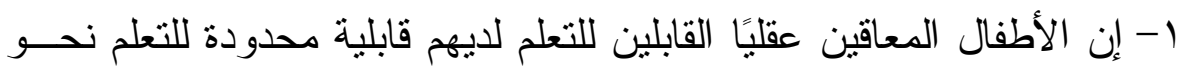

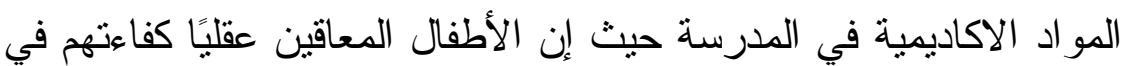
التعلم أقل من الأطفال الأخرين. وبينما ينضجون ويتقنون مهار ات الحات الحياة اليومية تظهر حاجاتهم للذهاب إلي المدرسة كباقي الأطفال . 
ז- لديهم القرة علي اكتساب مهار ات التكيف الاجتماعي بحيــث بـصبحون

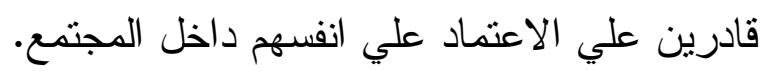

r- لديهم أقل كفاءة مهنية إذا ما تو افرت لهم فرص التنريب وتتمية المهار ات اتل

اللازمة فإنهم يصبحون قادرين علي إعالة أنفسهر .

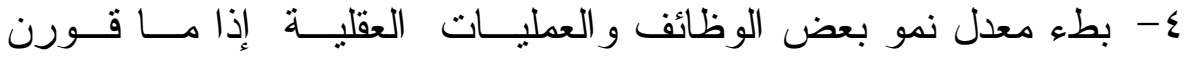

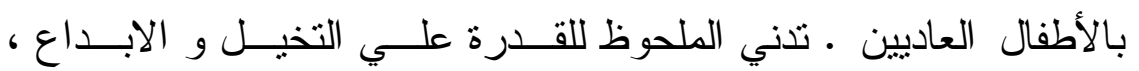

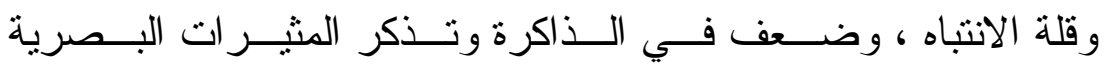

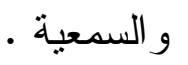

0- تأخر في النمو اللغة و الكلام فإن الأطفال المعاقين عقليًا القابلين للــتعلم

لديهم قدر ات لغوية محدودة ، فلديهم اضطر ابات لغوية متتوعة حيث إنهم

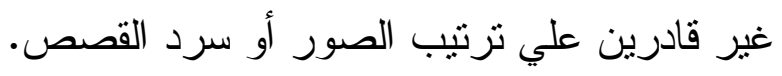

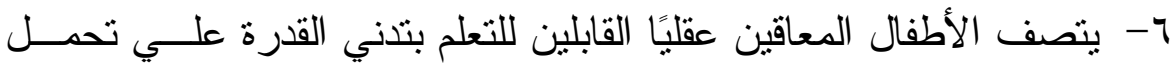

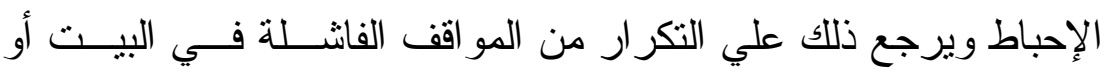

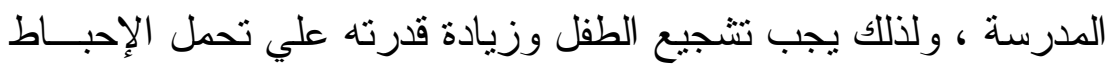

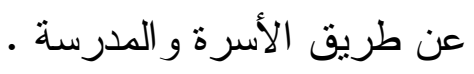

- يعاني الطفل القابل للتعلم من انحر افات ومشاكل سلوكية بنسبة أعلي مما

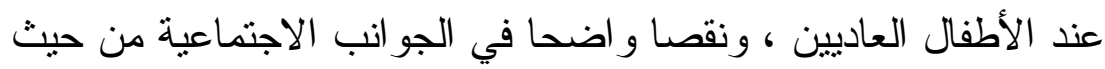

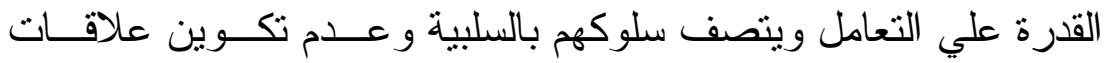

$$
\text { اجتماعية مع أقر انهم العاديين. }
$$

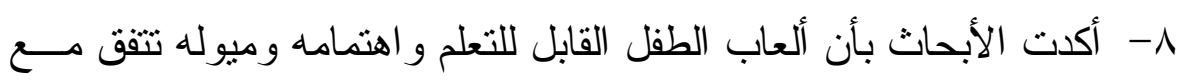

الأطفال العاديين نفس مستوي عمره العقلي لا عمره الزمني. 
9- يتميز الأطفال القابلين للتعلم من مشكلات حسية بمقارنة بزملائه ، التهان

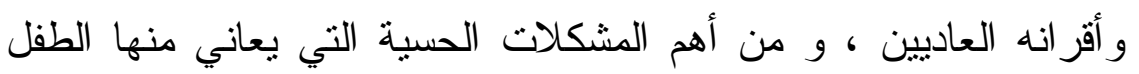

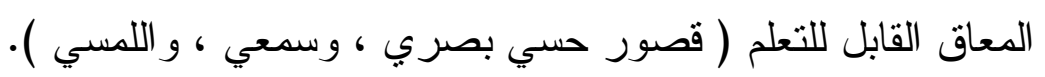
طرق واساليب تعليم المعاقين عقليا :

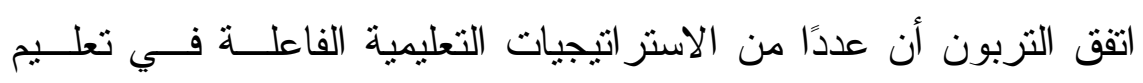

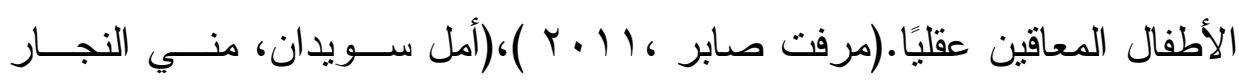

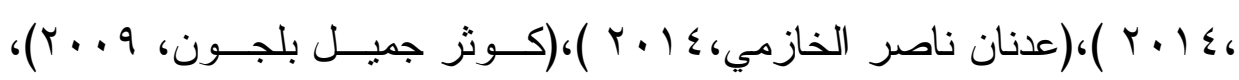

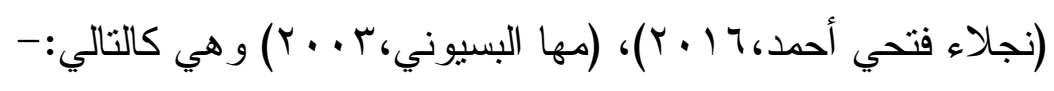

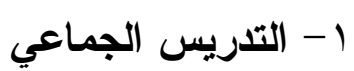

من أفضل الاستر اتيجيات التي يمكن استخدامها مـــع الأطفــال المعـاقين

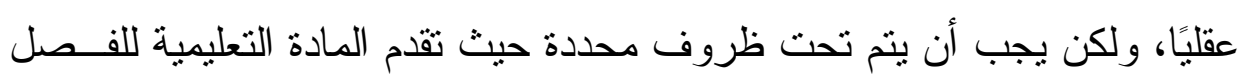
، ومن ثم تتاح فرصة التعلم التعاوني. r- الحوار و النقاش

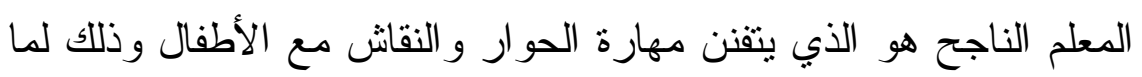

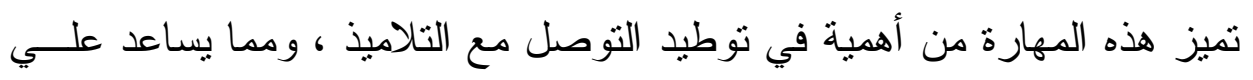

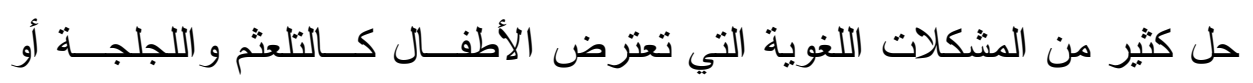
التأتأة، وذلك لأنه يناقش ويحاور بحرية مع المعلم ومع زملائه الأخرين.

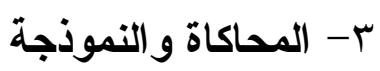

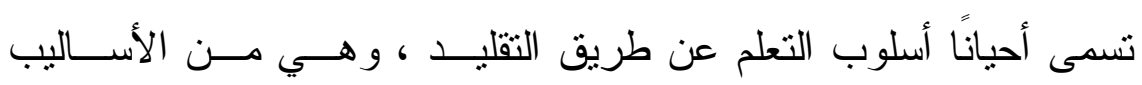

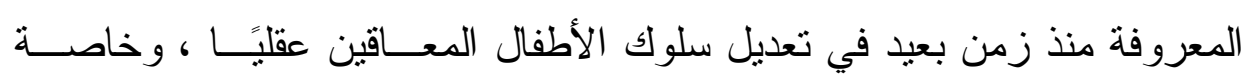

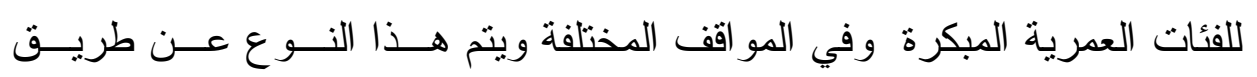
الملاحظة و التقليد من خلال ملاحظة الطفل للمعلم أو الو الدين و التلفاز . 
ع - التعلم باللعب

إن استخدام التعلم باللعب يجعل للطفل دورًا إيجابيًا يتميز بكونه عنــرًا

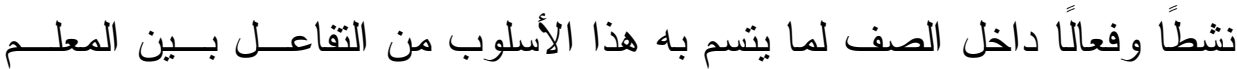
و الأطفال خلال العملية التعليمية وذلك من خلال أنشطة و ألعــاب تعليميــة ثــم إعدادها بطريقة منظمة مما يساعد الطفل علي اكتـساب الــسلوكيات الإيجابيــة

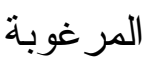

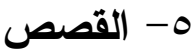

طريقة تعليمية تقوم علي العرض الحسي المعبر ، و الذي يتبعه المعلم مع الأطفال فلا بد لتعليمهم حقائق ومعلومات عن شخصية أو مو اقف أو ظـــاهرة أو حادثة معينة بقالب تمثيلي أو قد تستخدم قيم أو مبادئ أو اتجاهات مدــا تـسهر القصة علي إكساب الطفل الكثير من المتر ادفات اللغوية ،وتعمل علـي غــرس السلوكيات الحميدة المرغوبة ، وتتفس عن بعض العو اطف و المشـاعر المكبوتــة في نفوس الأطفال. السلوك الايجابي يري عبدالله صالح مخلف (10 ـ ب)السلوك الايجابي أبي سلوك تطــوعي يقوم به الطفل المعاق عقليًا القابل للتعليم بهدف تحقيق مساعدة اجتماعيــة فــي

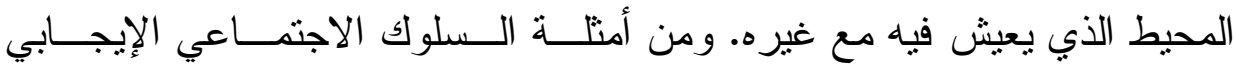
التعاون وهو السلوك الذي يشترك فيه الطفل المعاق عقليًا القابل للتعلــيم بــشكل تطوعي مع غيره لمساعدته فيما يقوم به من عمل . 
وتضيف الباحثة أن السلوك الإيجابي يشمل مجموعــة مــن الــسلوكيات

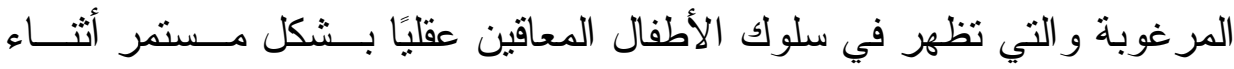

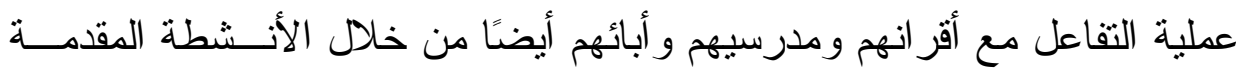

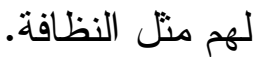
مسرح الطقل

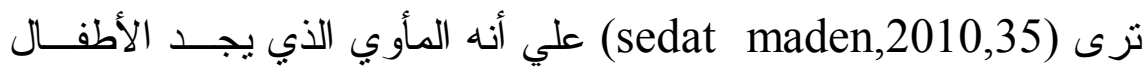
أنفسهم فيه فالطفل فيه ركنُ رئيسي سواء ممثل أو من الجمهور في كلتا الحالتين ينبغي أن يؤثر التمثيل في الطفل. يعد مسرح الطفل بأنه أحد مداخل التكريس فهو أداة من أدوات الفن التـي تستخدم بطريقة مخططة لتتمية المهارات المعرفيــة عنــدما تعجـز الوســـائل

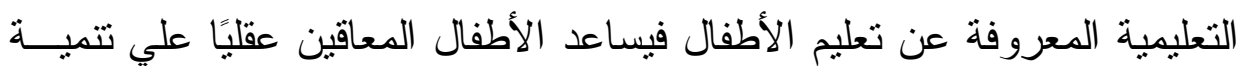
سلوكيات إيجابية يمكن الاستفادة منها في المو اقف المختلفة.

$$
\text { انواع مسرح الطفل : المسرح البشري: }
$$

و هو ذللك المسرح الذي يكون المؤدون خلاله هم الآدميون ، سو اء أكسان

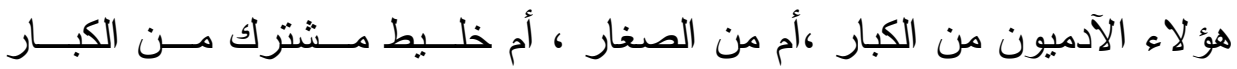

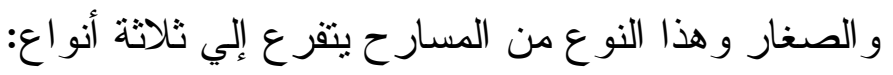

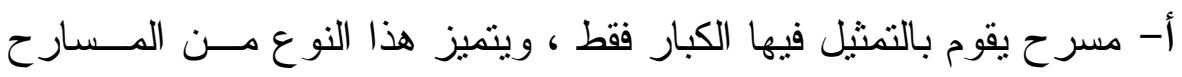

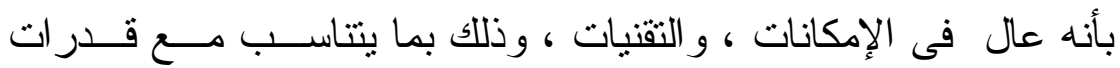
الممتلين الكبار ، و مهارتهم ، فهذا النوع يعتمد علــي إككانـات الأداء

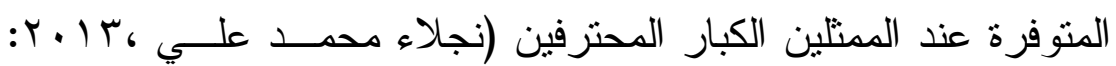
$(\wedge \wedge$ 
ب- مسر ح يقوم بالتمثيل فيها الأطفال، يعتمد هــذا النــوع مــن المـسـارح علي أداء الأدوار التمثيلية علي خشبة المسر ح ، سواء أكــان الجمهــور من الأطفال و الكبار ،فهو ذلك المـسر ح الــذي يــؤدي أدواره جماعـــة من الأطفال ، ويقدم أداء للتقرج الطفل ، أو أن يقدم لجمهــور مــشترك من الكبار ، و الــصغار ، ويتهـم هـــا النــوع مــن المـسـار ح بأنــهـ

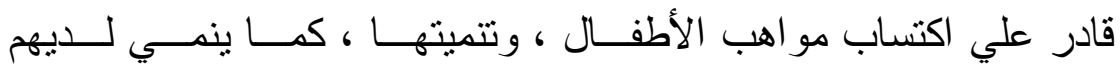
قيمة العمل الجماعي ويشعر هم بأهمية التعاون (هــدي قنــاوي، ؛ 99 ) : $(r \leq 0$

ج- مسرح يقوم بالتمثيل فيها الأطفال إلي جانب الكبار في هذا النــوع مــن المسار ح البشرية يشترك الأطفال مع الكبار في تقديم العرض المسرحي فهو ذلك المسرح الذي يجمع بين الكبــار والــصغار كممنلـين فــوق

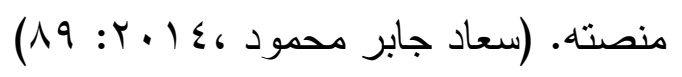
ب - المسرح العرائسي : - المي

ويتسم هذا النوع من المسارح بأنه أكثر حرية من المسسرح البـشري ، وذلك لاعتماده علي شخصيات متخيلة ،أبدعها خيال المؤلف ، وصنعتها موهبــة

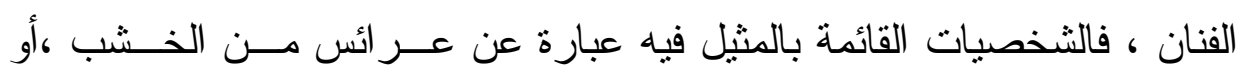
الورق ، أو البلاستيك ، أو القماش علي هيئة شكل بشري ،أو حيو اني ،وبحجــ يتتاسب و المسرح الذي سيظهر فيه ، ويقوم بتحريكها لاعبون - مــن البـشر ويحركون عرائسهم بناء علي حوار ،ومؤثزات صوتيه ، ولقد تعـددت أنــواع عر ائس المسرح لتعدد أثناله و أحجامه ومن أهم أنو اعها: 


$$
\begin{aligned}
& \text { 1-العر ائس القفازية } \\
& \text { r- العر ائس العصا } \\
& \text { r-العر ائس الماريونت }
\end{aligned}
$$

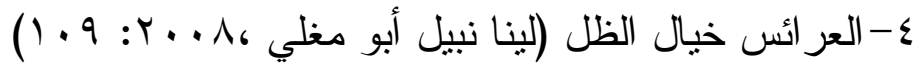

الدر اسات السابةة

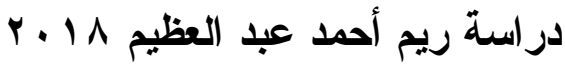

هدفت هذه الدر اسة إلي تتمية مهار ات التعبير الثشفوي ، و الحد مــن قلــق

التحدث لدى أطفال المرحلة الابتدائية للمعاقين عقلياً القابلين للتعلم ، حيث قامـــ الباحثة بإجر اء التجربة علي عينة تكونت من ( • () أطفــال تتــر اوح أعمــار هم

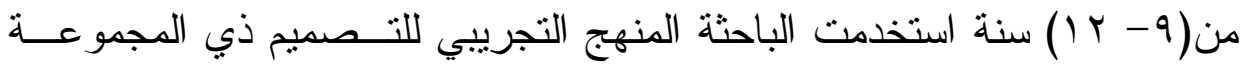
الو احدة ومن أدوات الدراسة اختبار التعبير الثفوي وبطاقة ملاحظة المرتبطة به - مقياس قلق التحدث من إعداد الباحثة - إعداد دليل المعلم - إعــداد برنــامج مقترح من إعداد الباحثة - كر اسات الأنـشطة و التــدريبات وتوصــلت نتــائج الدر اسة إلي فاعلية البرنامج المقترح في نتمية التعبير الـششفوي وخفـض قلــق التحدث لدى التلاميذ المعاقين عقليًا القابلين للتعلم.

دراسة إيمان خضر 1 ا ـ Y : هدفت هذه الدر اسة إلي معرفة مدي توظيف مسرح الطفل في تكوين البنية المعرفية بشتي المجالات لــدي طفـلـل الروضـــة، استخدمت الباحثة المنهج التجريبي للتصميم ذي المجموعة الواحــدة، ونكونــت عينة الدر اسة من(0 1 ) طفلًا وطفلة من المرحلة الثانية لريــاض الأطفــال وتــم القياس القبلي و البعدي لنفس العينة ،و أسفرت الدر اسة إلي أنه توجد فروق دلالــــة 
إحصائية بين القياس القبلي و البعدي في امتلاك الطفل بنية معرفية أساسية تتصل

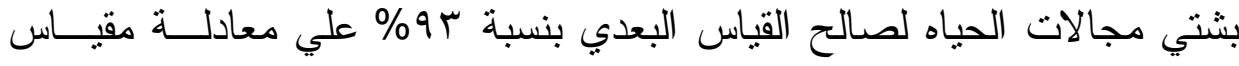
· التطوير دراسة روحية عبد الباسط 10 ـ بدفت هذه الدراسة إلي التعرف عالـي

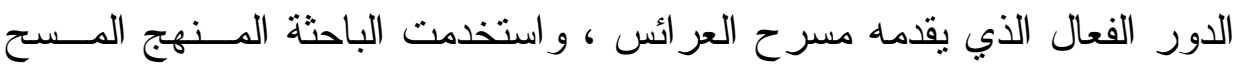

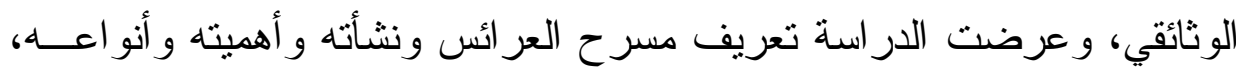

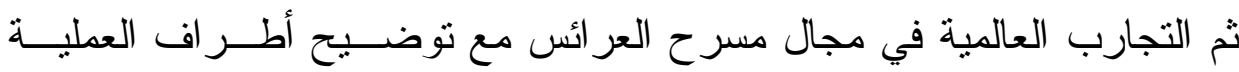

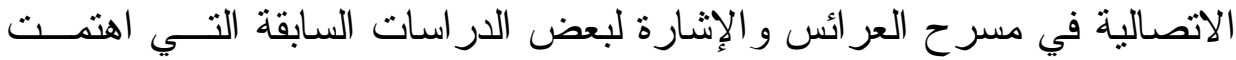

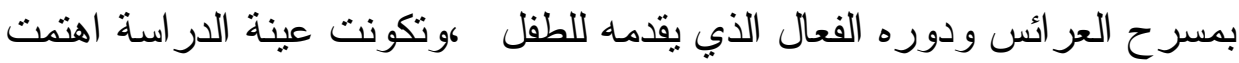

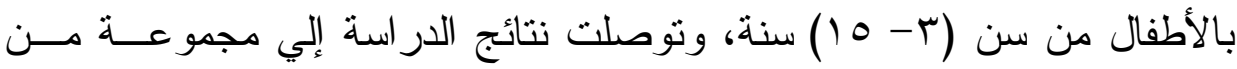

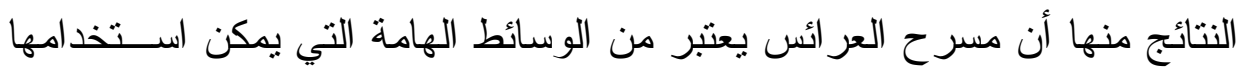

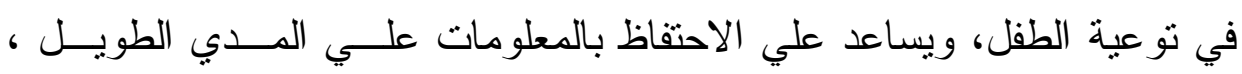

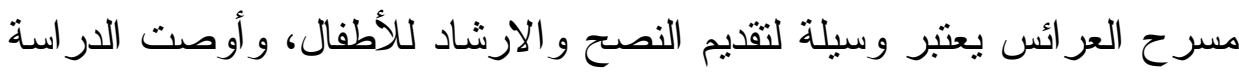
بضرورة التسبق بين المؤسسات التزبوية و التعليمية و الفنية و العلاجية للاســفادة

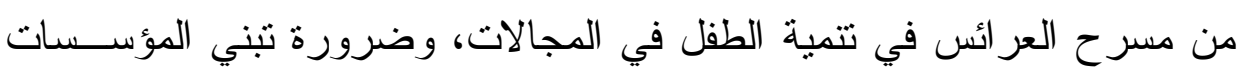

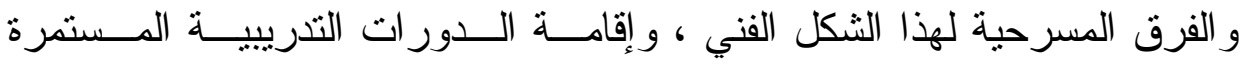
للعاملين في مجال مسرح العر ائس .

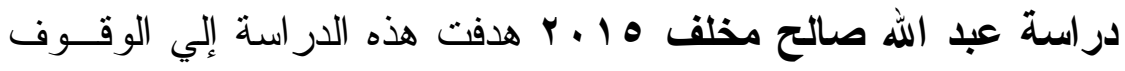

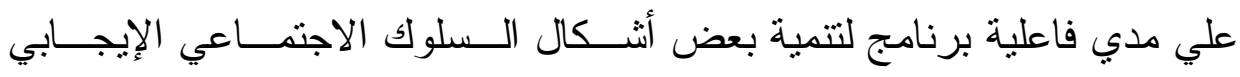
للأطفال المعاقين عقليًا ، و استخدم الباحث الدنهج التجريبي للتصميم المجمو عتين

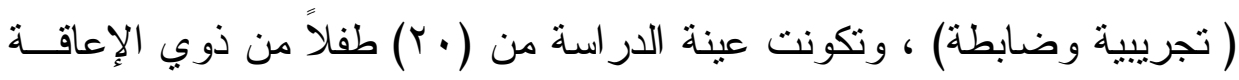

المجلد السادس


العقلية في المرحلة الابتدائية للتربية الفكرية وتــم تقـسيمهم إلـي (• (أطفــال مجموعة تجريبية ، أطفال مجموعة ضابطة ) وهم من الأطفال القابلين للتعلم

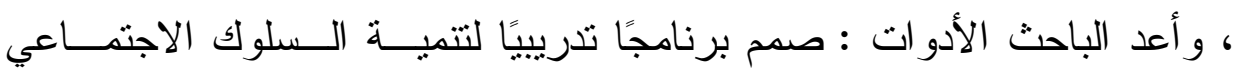
الإيجابي - مقياس السلوك الاجتماعي المصور - مقياس المسؤولية الاجتماعية

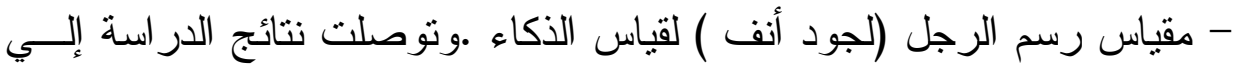

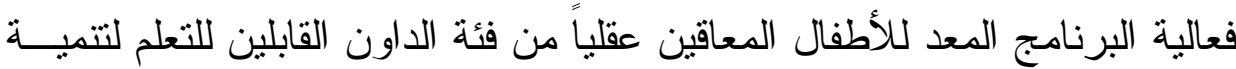

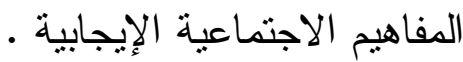

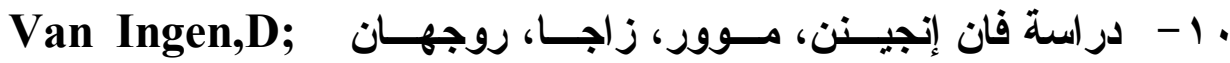

(Moorea, L; Zaja, R\& Rojahn, J.(2010

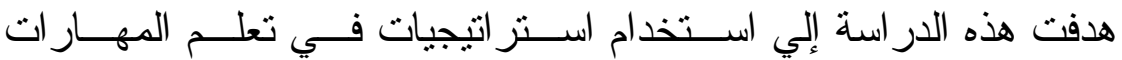
الأكاديمية، و الاضطر ابات السلوكية وذلك من خلال أساليب تدريسية باســتخدام

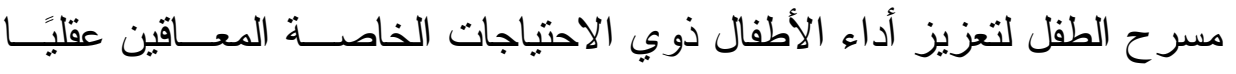
القابلين للتعلم. استخدمت الدراسة الدنهج التجريبي وتكونت عينة الدراســة مــن

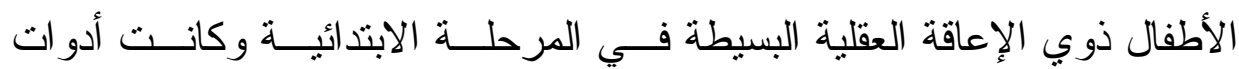
الدراسة مقياس الفهم - مقياس المهار ات الكلامية- النصوص المسرحية للأطفال - مقياس المهار ات الحسابية - قائمة لمسح المشكلات السلوكية وتوصلت نتـائج الدر اسة إلي أن التتوع في التدريس وتقديم تعزيز لهــؤل لاء الأطفــال باســتخدام أساليب تدريسية منل مسر ح الطفل يساعد ذلك علي تقدم الأطفال فـــي العمليـــة

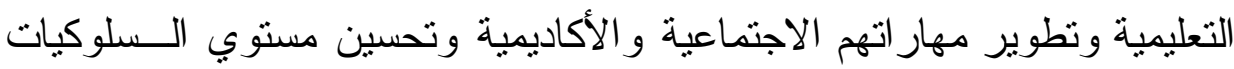
لديهم. 
Putnam,J.w\&Johson .Rt 2008 راسة بوتنام وجونسون

هدفت الدراسة إلي التعرف علي أثر الإرشادات الخاصة بمهار ات التعاون

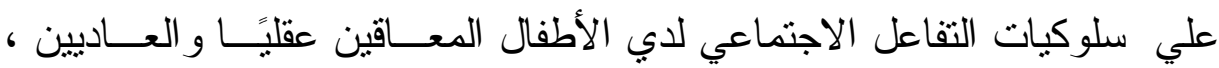

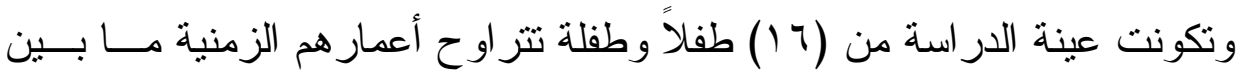

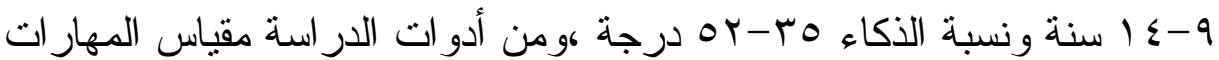
الاجتماعية ، ومقياس ستانفورد بينيه للذكاء، وتوصلت نتائج الدر اسة إلي وجــود

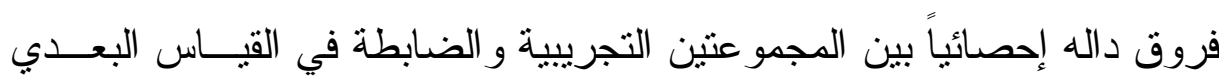

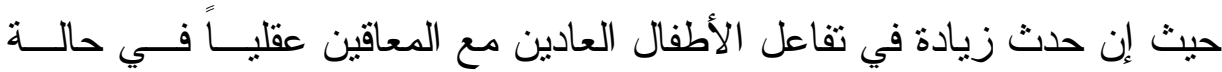

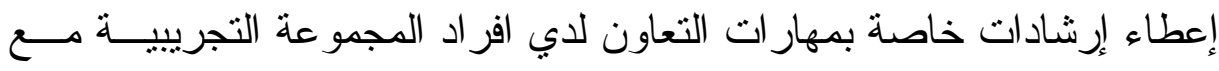
انخفاض في مستوي السلوكيات المرغوبة.

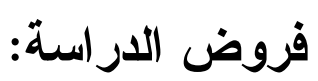

ا. توجد فروق دالة إحصائيا بين متوسطات رتب المجموعة التجريبية على

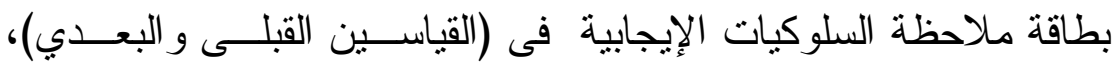
لكالح القياس ( البعدي).

r. لا نوجد فروق دالة إحصائيا بين متوسطات رثب المجموعة التجريييــة

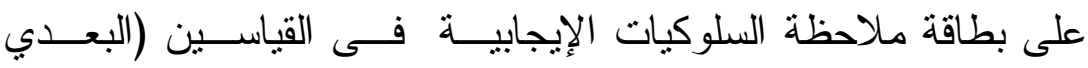

$$
\text { و التنتعي). }
$$

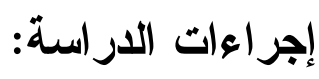

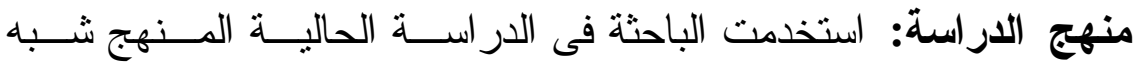

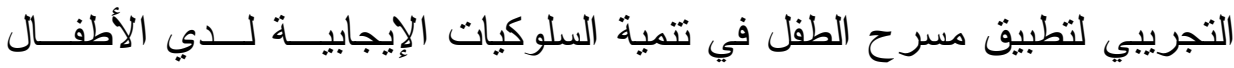


المعاقين عقليًا القابلين للتعلم ، و استخدمت الباحثة أحد أنو اع التصميمات البحثيــة فى المنهج شبه التجريبي وهو التصميم القبلى - البعدي- التتبعـي للمجموعــة التجريبية.

عينة الدراسة : تم اختيار عينة الدر اسة من الأطفــال المعـاقين عقليًا القابلين للتعلم بالمرحلة الابتدائية : مدرسة التزبية الفكرية بأجــا، خـــله العــام

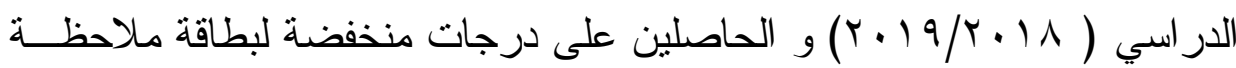
السلوكيات الإيجابية السية

وصف العينة :ضمت عينة البحث ( A ) أطفال من المعاقين عقليًا بالصف الر ابع الابتدائي ، معامل ذكائهم يتز اوح بـين (00-99) ، و وعمــرهم الزمنـى

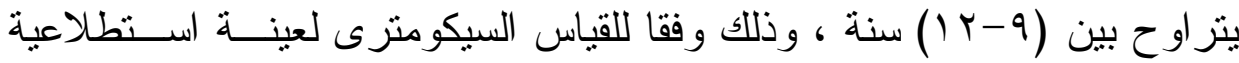
قو امها ( • ب) تلميذًا وتلميذة بالمرحلة الابتدائية بالصف الر ابع الابتدائي . أدوات الار اسـة.

اختبار الأكاء ستانفورد بينيه الصورة الخامسة ل ( جــال ـ ه. رويـــ ،

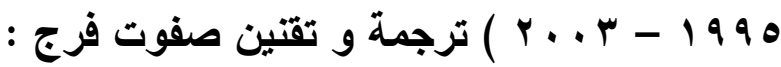

يهدف هذا المقياس إلى قياس نسبة الذكاء و القدر ات المعرفية وهو ملائــ

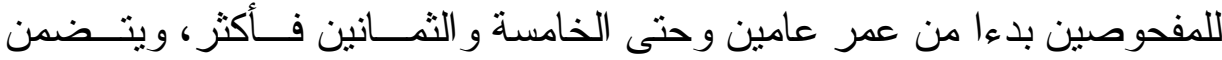
المقياس الكامل :أي نسبة الذكاء الكلبة، عشرة مقاييس فر عية، وتـــوفر توليفـات مختلفة بين هذه المقاييس الفرعية مقاييس أخرى، وتتضمن بطارية نسبة الــذكاء

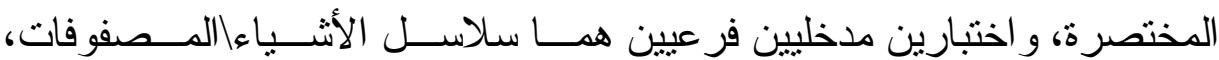
و المفردات، ويمكن استخدامه مع الصم، وضعاف السمع، و اضطر ا ب التو اصــل، 
و اضطر اب التوحد، وصعوبات التعلم، و إعاقات الثلل المخي، و الإصابات المخية الصدمية، وينقسم إلى مقياسين فرعيين هما :مقياس الذكاء اللفظي ومقياس الذكاء

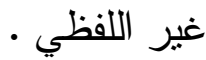

\section{() بطاقة ملاحظة السلوكيات الإيجابية : إعداد /الباحثة}

هدف البطاقة: تهدف هذه البطاقة لقياس السلوكيات الإيجابية لدى الأطفال

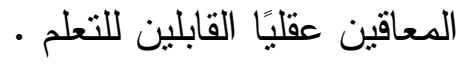

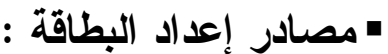

$$
\text { تم إعداد هذا البطاقة في ضوء : }
$$

1. المر اجع و البحوث و الدراسات السابقة التي أجريت على مرحلة الإبتدائية

وطبقت مقاييس السلوك الإيجابي للأطفال متل دراسة (أسماء عبد العسال

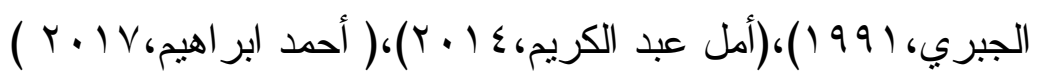

r. الاختبار ات و الدقاييس التي أعدت بطاقة الملاحظة السلوكيات الإيجابيــة

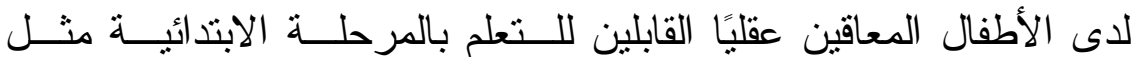

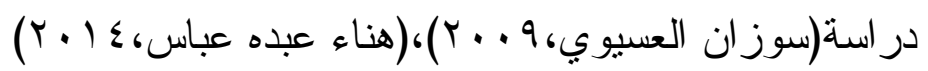

r. الخصائص النفسية و الاجتماعية و الجسمية و العقليــة للأطفــال المعـاقين

عقليًا القابلين للتعلم بالمرحلة الإبتدائية.

$$
\text { •طريقة التطبيق و التصحيح : }
$$

ا طريقة التطبيق : تطبق البطاقة بصورة فردية ، و لا يوجد زمسـن محسدد

$$
\text { للإجابة عن البطاقة . }
$$




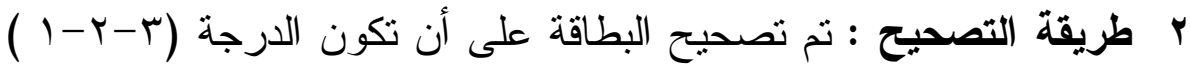

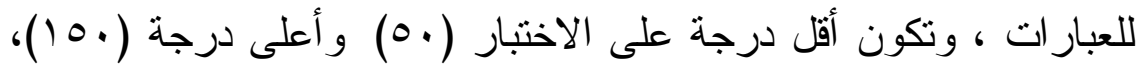

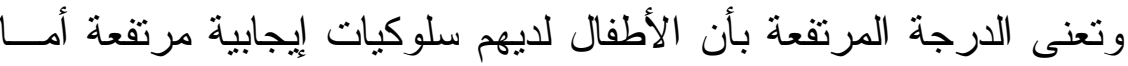
الدرجة المنخفضة فتعنى أن الأطفال لديهم سلوكيات إيجابية منخفضة. وصف البطاقة فى صورة النهائية :تتكون البطاقة مسن (.0) عبـارة موز عة على أبعاد بطاقة الملاحظة السلوكيات الإيجابية للأطفال الإعاقة العقليــة

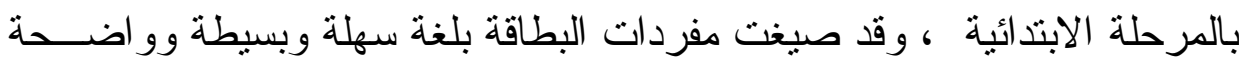
بحيث تكون الإجابة عن طريق الثخص نفسه أو أمهات الابناء صدق وثبات بطاقة ملاحظة السلوكيات الإيجابية : - الصدق : اتبعت الباحثة عدة إجر اءات للتحقق مـن صــدق الإياله : الأداة هـى :

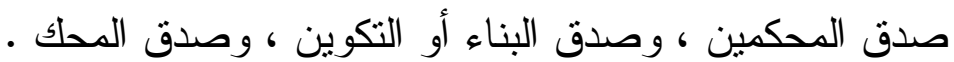
فيما يتعلق بصدق المحكمين فقد اعتمدت الباحثة علــى أر اء عـدد مـن

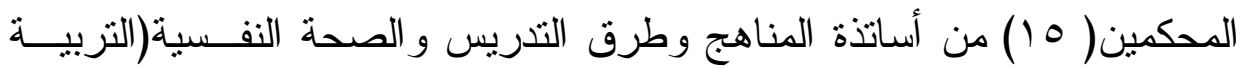

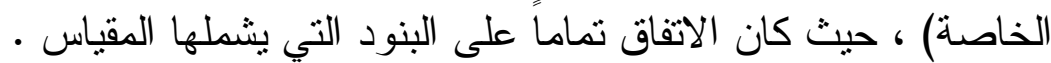
و أما بالنسبة لصدق البناء أو التكوين ويقصد به صدق الاتساق الــداخلي

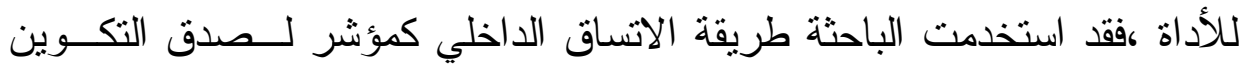
الفرضي للبطاقة ، حيث حسب معاملات ارتباط درجة كل مفردة بدرجة البعـــ الذى تتتمى إليه ، وكذللك معاملات ارتباط درجة كل بعد مــن أبعـاد البطاةـــة

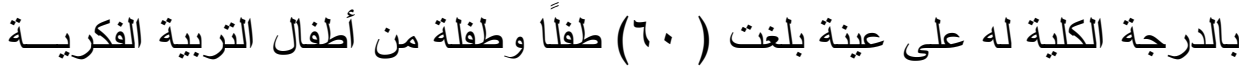

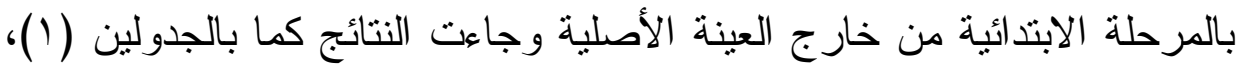

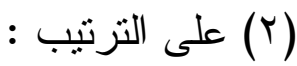

المجلد السادس


جدول رقم (1)

قيم معاملات الارتباط بين درجة المفردة ودرجة البعد الأى تنتمى إليها

\begin{tabular}{|c|c|c|c|c|c|c|c|c|}
\hline \multicolumn{8}{|c|}{ العبارات } & السلوك \\
\hline v & 1 & 0 & $\varepsilon$ & $r$ & $r$ & 1 & رقم العبارة & \multirow[t]{2}{*}{ النظافة } \\
\hline \multirow[t]{5}{*}{$", \| \wedge \wedge r$} & $\because, \leqslant$ or & ".,., I I & $* ., 711$ & ${ }^{*} \cdot,, 0 \wedge \mathrm{V}$ & 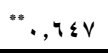 & "., OrV & معامل الارتباط & \\
\hline & & & 11 & 1. & 9 & $\wedge$ & رقم العبارة & \multirow[t]{2}{*}{ الطاعة } \\
\hline & & & $" \cdot, \wedge \wedge 1$ & $" ., 0 Y \Lambda$ & " & $\because, \leqslant \circ v$ & معامل الارتباط & \\
\hline & & 17 & 10 & $1 \varepsilon$ & $1 \pi$ & ir & رقم العبارة & \multirow{2}{*}{ زيارة } \\
\hline & & ".,orr & $\because \cdot, \uparrow \wedge q$ & $\because, 0 \leq V$ & $\because \leqslant 0 V$ & $" \cdot$, orv & معامل الارتباط & \\
\hline$r r$ & rr & $r$ & $r$. & 19 & 11 & IV & رقم العبارة & \multirow{2}{*}{ علي الأطعمة } \\
\hline \multirow[t]{3}{*}{$\because ., 791$} & $\because \cdot \wedge 91$ & $" \cdot, ., 4 \wedge 9$ & $* \cdot, v r)$ & ".,ort & $\because \cdot, 7 \wedge 9$ & $\because,\{\circ \vee V$ & معامل الارتباط & \\
\hline & & & rV & Y & ro & $r \varepsilon$ & رقم العبارة & \multirow{2}{*}{ علي الأشطظة المافظة } \\
\hline & & & $" \cdot, 0 \wedge v$ & $* ., T \leqslant V$ & "., OrV & $" ., 011$ & معامل الارتباط & \\
\hline & & & & $r$. & rq & rA & رقم العبارة & \multirow[t]{2}{*}{ النظام } \\
\hline & & & & $\because, \wedge \wedge 1$ & ".,OYA & מצו, ". & معامل الارتباط & \\
\hline & & & & r & rr & $r$ & رقم العبارة & \multirow{2}{*}{ بالحيوان } \\
\hline & & & ".,orr & $* ., 7 \wedge 9$ & $" \cdot, T \leqslant V$ & "., O P V & معامل الارتباط & \\
\hline & & ra & rA & rv & ri & ro & رقم العبارة & \multirow[t]{2}{*}{ الصدق } \\
\hline & & $\because ., 4 \wedge 9$ & ${ }^{*} \cdot, V Y I$ & ".,orr & $" \cdot, \uparrow \wedge 9$ & $* *, 0 \wedge V$ & معامل الارتباط & \\
\hline & & & $\varepsilon r$ & $\varepsilon r$ & \&1 & $\varepsilon$. & رقم العبارة & \multirow{2}{*}{ آلآدتئاب } \\
\hline & & & "*.,074 & $* ., \varepsilon \wedge \vee$ & $\because$, , & "., Or & معامل الارتباط & \\
\hline & & & $\leqslant v$ & $\leqslant 4$ & $\leq 0$ & ؛ & رقم العبارة & \multirow[t]{2}{*}{ إتقان العمل } \\
\hline & & & $* ., 001$ & "., OrA & $* \cdot \wedge \leqslant \vee$ & $\because, v \circ \leq$ & معامل الارتباط & \\
\hline & & & & o. & $\leqslant 9$ & $\varepsilon \wedge$ & رقم العبارة & \multirow[t]{2}{*}{ التو اضع } \\
\hline & & & & $\because, 79 \wedge$ & מוז," & אזו,."• & معامل الارتباط & \\
\hline
\end{tabular}

(") (") دالة عند مستوى الدالة ( ه ., , . ) (") دالة عند مستوى الدالة ( 1 ( ., ·.) 
يتضح من نتائج الجدول السابق ان قيم معامل ارنباط درجة كـلـ مفــردة بالدرجة الكلية لسلوكيات التي تتنمي اليها في بطاقة الملاحظة دالة احصائًا، وقد

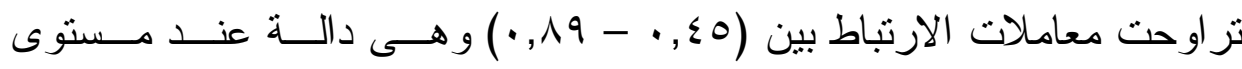

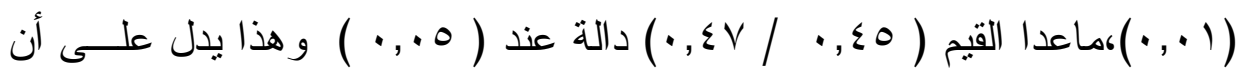

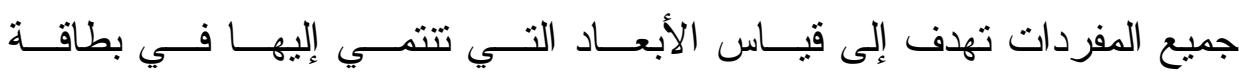

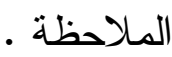

$$
\text { جدول رقم (r) }
$$

قيم معاملات الارتباط درجة كل بعد بالدرجة الكلية للبطاقة

\begin{tabular}{|c|c|c|}
\hline مستوى الدلالة & معامل الارتباط & السلوك الإيجابي \\
\hline$\cdot, \cdot 1$ & $\cdot, V Y I$ & النظافة \\
\hline$\cdot, \cdot 1$ & $\cdot, \vee \vee \vee$ & الطاعة الطاعة \\
\hline$\cdot, \cdot 1$ & $\cdot, V \leq \uparrow$ & زيارة المريض \\
\hline$\cdot, \cdot 1$ & •, TY & المحافظة علي الأطعمة \\
\hline$\cdot, \cdot 1$ &., 011 & المحافظة علي الأشطة الرياضة \\
\hline$\cdot, \cdot 1$ & $\cdot, 711$ & النظام \\
\hline$\cdot, \cdot 1$ &., 007 & الرفق بالحيوان \\
\hline$\cdot, \cdot 1$ & $\cdot, \uparrow \wedge \wedge$ & 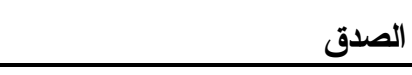 \\
\hline$\cdot, \cdot 1$ & $\cdot, V Y \leq$ & آداب الاستئذان \\
\hline$\cdot, \cdot 1$ & $\cdot, \pi / r$ & إتقان العمل \\
\hline$\cdot, \cdot 1$ & $\cdot, \pi / \mu$ & التو اضع \\
\hline$\cdot, \cdot 1$ & $\cdot, \wedge Y I$ & الارجة الكلية \\
\hline
\end{tabular}


يتضح من الجدول السابق أن قيم معاملات ارتباط كل بعد بالدرجة

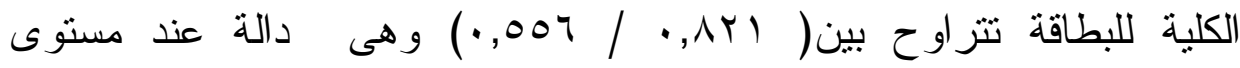
$(\cdot, \cdot 1)$

أما فيما يخص صدق المحك ، فقد تم حسساب معامـل الارنبـــاط بـين

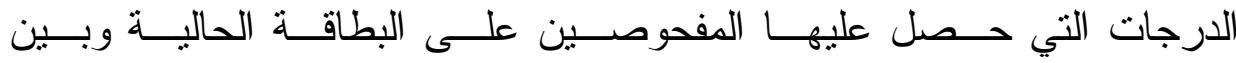

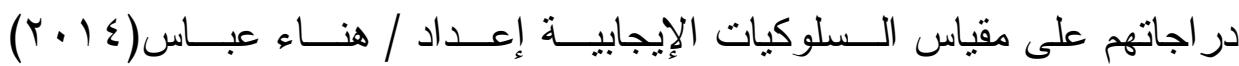

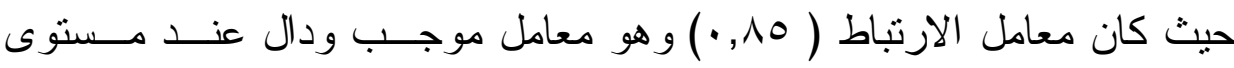
$\cdot(\cdot, \cdot 1)$

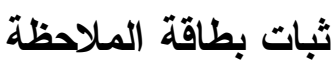

قامت الباحثة بحساب ثبات البطاقة بطريقتين، طريقة إعـادة الاختبـار

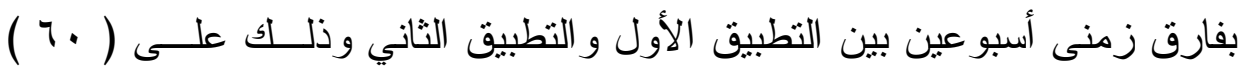

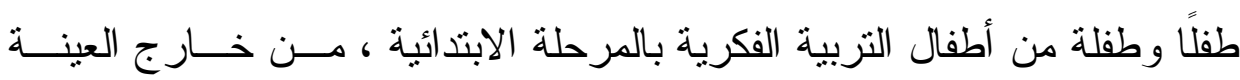

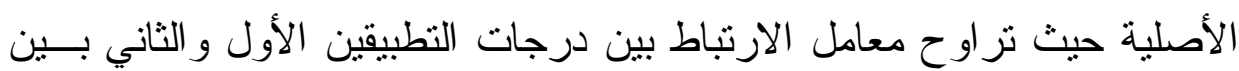

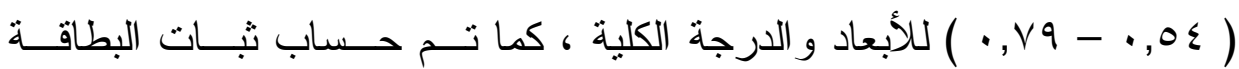

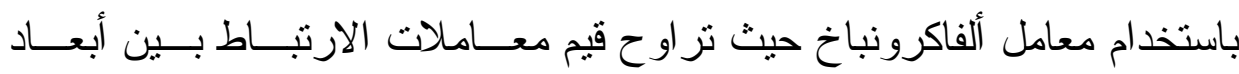

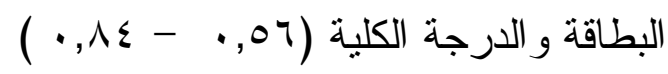


جدول رقم (r)

قيم معاملات ثبات أبعاد البطاقة و الارجة الكلية بطرق إعادة

التطبيق ومعامل ألفا كرونباخ ولئ ولئ

\begin{tabular}{|c|c|c|c|}
\hline إعادة الاختبار & (الفاكرونباخ & عدد المفردات & السلوك الإيجابي \\
\hline ., TrR & $\cdot, V Y I$ & $v$ & النظافة \\
\hline., $0 \leq r$ &., $71 r$ & $\varepsilon$ & الطاعة \\
\hline., 091 &., 701 & - & زيارة المريض \\
\hline., $0 \wedge r$ &., $01 r$ & $\mathrm{v}$ & المحافظة علي الأطعمة \\
\hline$\cdot, 0 \wedge \varepsilon$ &., $7 \mathrm{r}$ & $\varepsilon$ & المحافظة علي الأشطة الرياضة \\
\hline$\cdot, \vee \vee 70$ & $\cdot, V \backslash r$ & $r$ & النظام \\
\hline$\cdot, 74$ & $\cdot, \wedge 11$ & $\varepsilon$ & الرفق بالحيوان \\
\hline$\cdot, V \cdot r$ & $\cdot, 0 \wedge 1$ & $\bullet$ & الصدق \\
\hline . &., $09 r$ & $\varepsilon$ & آداب الاستئذان \\
\hline., 001 & - tirt & $\varepsilon$ & إتقان العقل \\
\hline$\cdot, \times 11$ & $\cdot, V Y_{1}$ & $r$ & التو اضع \\
\hline$\cdot, \vee \vee 91$ & $\cdot, \wedge \leq 1$ & $\circ$. & الارجة الكلية \\
\hline
\end{tabular}

تثنير نتائج الجدول (T) إلى أن البطاقة على درجة مقبولة مــن الثبــات تبرر استخدامه في الدراسة الحالة . نتائج الار اسة ومناقشتها و تفسيرها. : ائتج الفرض الأول : نص الفرض الأول على : " توجد فـروق ذات دلالـــة إحــصائية بــين

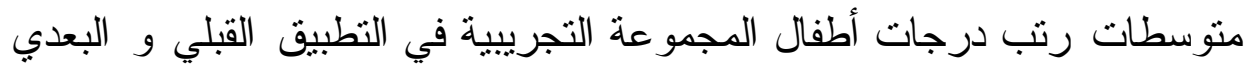
لبطاقة ملاحظة السلوكيات الإيجابية لصالح القياس البعدى ". 


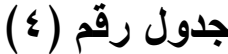

يوضح الفروق بين متوسطات رتب درجات أفر اد المجموعة التجريبية في التطبيق القبلي والبعدي لبطاقة ملاحظة السلوكيات الإيجابية باستخدام

ولكوكسن Wilcoxon

\begin{tabular}{|c|c|c|c|c|c|c|}
\hline التأثير & مستوى الدلامة & $\mathbf{Z}$ & مجموع & متوسط الرتب & القبلى ـ البعدى القياس & السلوك الإيجابي \\
\hline 0.897 & 0.05 & 2.539 & $\begin{array}{c}.00 \\
36.00\end{array}$ & $\begin{array}{c}.00 \\
4.50\end{array}$ & الرتب الرتب السالبة & النظافة \\
\hline 0.902 & 0.05 & 2.555 & $\begin{array}{c}.00 \\
36.00\end{array}$ & $\begin{array}{c}.00 \\
4.50\end{array}$ & الرتب السالبة & الطاعة \\
\hline 0.844 & 0.05 & 2.389 & $\begin{array}{c}1.00 \\
35.00\end{array}$ & $\begin{array}{l}1.00 \\
5.00\end{array}$ & الرتب الرتب السالبة & زيارة المريض \\
\hline 0.892 & 0.05 & 2.527 & $\begin{array}{c}.00 \\
36.00\end{array}$ & $\begin{array}{l}.00 \\
4.50\end{array}$ & الرتب الرتب الموجبة & الأطعمة \\
\hline 0.902 & 0.05 & 2.555 & $\begin{array}{c}.00 \\
36.00\end{array}$ & $\begin{array}{l}.00 \\
4.50\end{array}$ & الرتب الرتب السالبة & الأمحافظة الرعلي \\
\hline 0.897 & 0.05 & 2.539 & $\begin{array}{c}.00 \\
36.00\end{array}$ & $\begin{array}{c}.00 \\
4.50\end{array}$ & الرتب الرتب السالبة & النظام \\
\hline 0.843 & 0.05 & 2.388 & $\begin{array}{c}.00 \\
28.00 \\
\end{array}$ & $\begin{array}{c}.00 \\
4.00 \\
\end{array}$ & الرتب الرتب السالبة & الرفق بالحيوان \\
\hline 0.900 & 0.05 & 2.549 & $\begin{array}{c}.00 \\
36.00\end{array}$ & $\begin{array}{c}.00 \\
4.50\end{array}$ & الرتب الرتب السالبة & الصدق \\
\hline 0.897 & 0.05 & 2.539 & $\begin{array}{c}.00 \\
36.00 \\
\end{array}$ & $\begin{array}{c}.00 \\
4.50\end{array}$ & الرتب الرتب السالبة & آداب الاستئذان \\
\hline 0.906 & 0.05 & 2.565 & $\begin{array}{c}.00 \\
36.00 \\
\end{array}$ & $\begin{array}{c}.00 \\
4.50 \\
\end{array}$ & الرتب الرتب السالبة & اتقان العمل \\
\hline 0.899 & 0.05 & 2.546 & $\begin{array}{c}.00 \\
36.00 \\
\end{array}$ & $\begin{array}{c}.00 \\
4.50\end{array}$ & الرتب الرتب الموالبة & التو اضع \\
\hline 0.891 & 0.05 & 2.524 & $\begin{array}{c}.00 \\
36.00\end{array}$ & $\begin{array}{c}.00 \\
4.50\end{array}$ & الرتب الرتبالبة الموجبة & الارجة الكلية \\
\hline
\end{tabular}




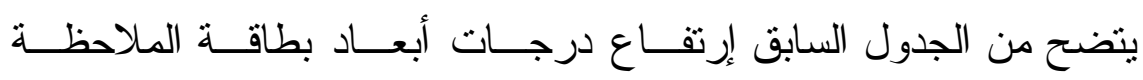

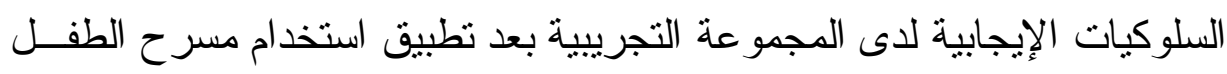
حيث وجد أن جميع قيم "Z"للفروق بين منوسطات رثب درجات التطبيقين القبلي

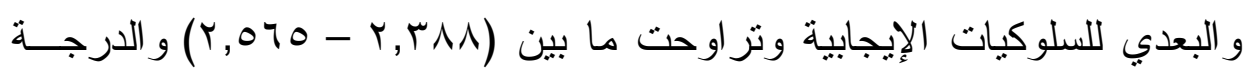

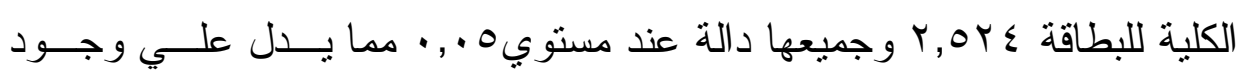

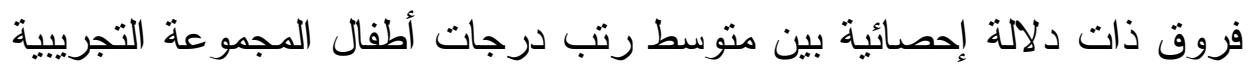

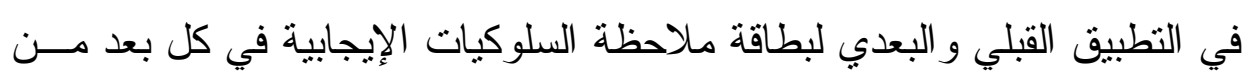

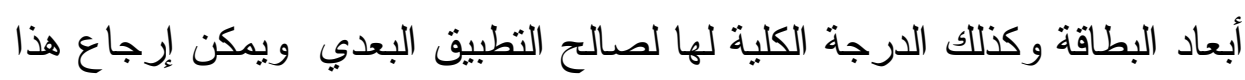

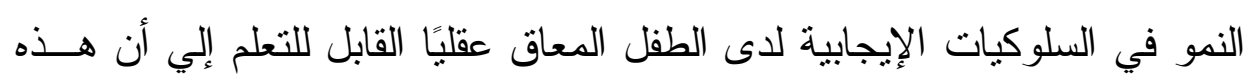

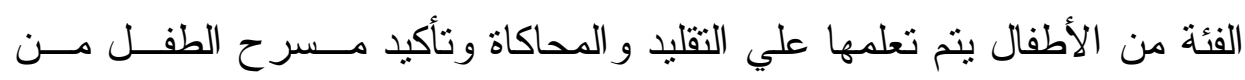
خلال الأنشطة المسرحية المستخدمة لتلك السلوكيات الإيجابية قد أسهم تـشكيل

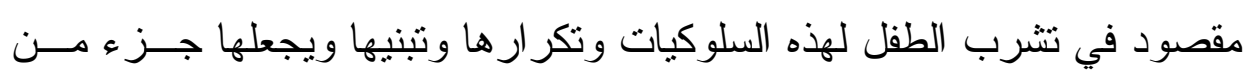

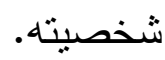
نتائج الفرض الثاني: نص الفرض الثاني على : " لا توجد فروق ذات دلالـــة إحـصـائية بــين

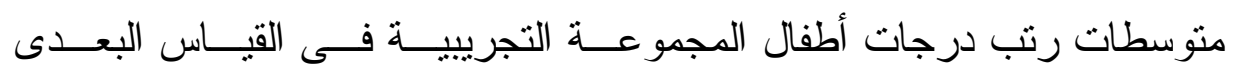

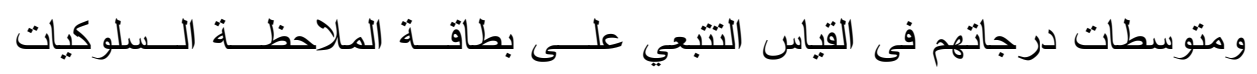
الإيجابية".

\footnotetext{
العدد الأول : يوليو 19.r.
}

$1 \cdot r$

المجلد السادس 


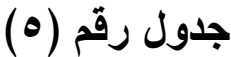

يوضح الفروق بين متوسطات رتب درجات أفراد المجموعة التجريبية في القياسين البعدي والتتبعي لبطاقة الملاحظة السلوكيات الإيجابية باستخدام

ولكوكسن Wilcoxon

\begin{tabular}{|c|c|c|c|c|c|}
\hline مستوى & $\mathbf{Z}$ & مجموع & متوسط & البعدى ـ القياس التبعي & السلوك الإيجابي \\
\hline غير دالة & 1.342 & $\begin{array}{c}3.00 \\
.00\end{array}$ & $\begin{array}{l}1.50 \\
.00\end{array}$ & الرتب المبت السالبة & النظافة \\
\hline غير دالة & .000 & $\begin{array}{l}.00 \\
.00\end{array}$ & $\begin{array}{l}.00 \\
.00\end{array}$ & الرتب الرتب السالبة & الطاعة \\
\hline غير دالة & 1.000 & $\begin{array}{c}1.00 \\
.00\end{array}$ & $\begin{array}{c}1.00 \\
.00\end{array}$ & الرتب الرتب الموجبة & زيارة المريض \\
\hline غير دالة & 1.382 & $\begin{array}{l}17.00 \\
4.00\end{array}$ & $\begin{array}{l}3.40 \\
4.00\end{array}$ & الرتب الموجبة السالبة & المحافظة علي الأطعمة \\
\hline غير دالة & 1.000 & $\begin{array}{c}1.00 \\
.00\end{array}$ & $\begin{array}{l}1.00 \\
.00\end{array}$ & الرتب الموجبة السالبة & المحافظة علي الأشطة \\
\hline غير دالة & 1.000 & $\begin{array}{l}.00 \\
1.00\end{array}$ & $\begin{array}{l}.00 \\
1.00\end{array}$ & الرتب الموجبة السالبة & النظام \\
\hline غير دالة & 1.000 & $\begin{array}{c}.00 \\
1.00 \\
\end{array}$ & $\begin{array}{l}.00 \\
1.00\end{array}$ & الرتب الرتب السالبة & الرفق بالحيوان \\
\hline غير دالة & 1.342 & $\begin{array}{c}3.00 \\
.00\end{array}$ & $\begin{array}{l}1.50 \\
.00\end{array}$ & الرتب الرتب الموجبة & الصدق \\
\hline غير دالة & 1.000 & $\begin{array}{l}.00 \\
.00\end{array}$ & $\begin{array}{l}.00 \\
.00\end{array}$ & الرتب الرتب السالبة & آداب الاستئذان \\
\hline غير دالة & .000 & $\begin{array}{l}.00 \\
.00\end{array}$ & $\begin{array}{l}.00 \\
.00\end{array}$ & الرتب المتب السالبة & اتقان العمل \\
\hline غير دالة & .000 & $\begin{array}{l}.00 \\
.00 \\
\end{array}$ & $\begin{array}{l}.00 \\
.00 \\
\end{array}$ & الرتب المبوتبة السالبة & التو اضع \\
\hline 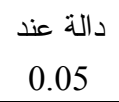 & 2.023 & $\begin{array}{c}15.00 \\
.00\end{array}$ & $\begin{array}{c}3.00 \\
.00\end{array}$ & الرتب الرتب السالبة & الارجة الكلية \\
\hline
\end{tabular}


يتضح من الجدول السابق عدم وجود فروق دالة إحصائية لقيمة (Z) فـي

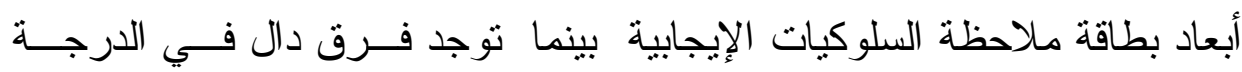

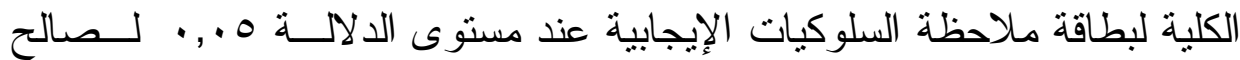

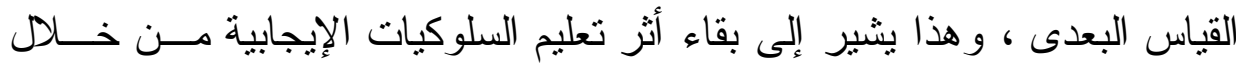

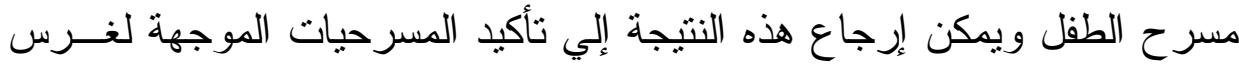

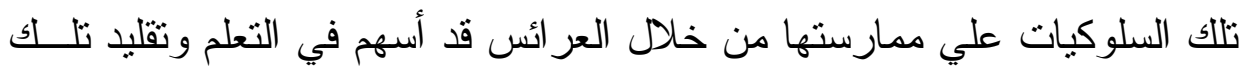

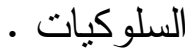

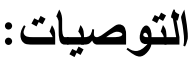

في ضوء ما توصل إليه البحث من نتائج يمكن الإثشارة إلي التوصيات التالية: • ضرورة الاهتمام بمسر ح الطفل بصفة عامة ومسر ح العر ائس بصفة خاصة وتفعيل دوره في مدارس التربية الفكرية.

• ضرورة الاهتمام بالعروض المسرحية المتتوعة لتتمية السلوكيات الإيجابية.

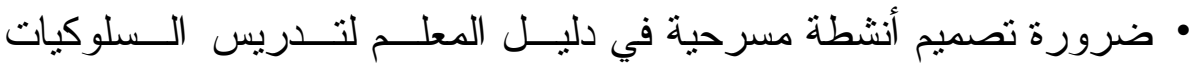

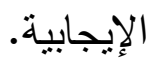

• ت توفير أنو اع متعددة من مسار ح الأطفال بمدارس التربية الفكرية للاســتفادة منها في تتمية السلوك الإيجابي. • إنشاء أقسام خاصة بالمسرح بكلية التربية النوعية قسم التزبية الفنــــة تهـتم بصناعة عروسة مميزة للطفل المعاق. • إقامة الدورات التدرييية المستمرة للعاملين في التربية الفكرية فــي مجــال مسرح الأطفال. 
من خلا نتائج الدراسة الحالية أمكن للباحثة طرح مجموعة من الدراسات

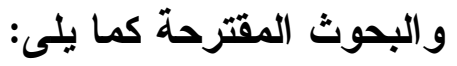

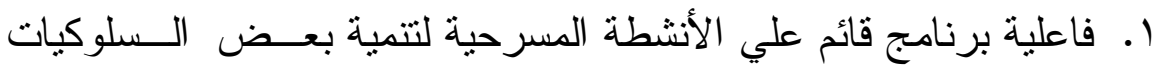

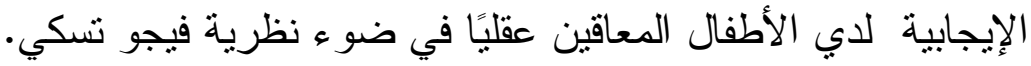

r. فعالية استخدام عر ائس المارونت في اكساب الأطفال المعـاقين عقليًا بعض القيم الاجتماعية و الاخلاقية.

؛. فعالية استخدام مسرح الطفل في تتمية مفهوم الانتــــاء لــدي الأطفــال المعاقين عقليًا القابلين للتعلم. 0. فعالية استخدام العروض المسرحية في اكساب مفهوم الأمن والـسلامة

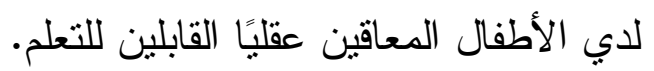
7. فعالية برنامج تدرييي مقتر ح لمعلمي التربية الفكرية لتتميــة الكفايــات

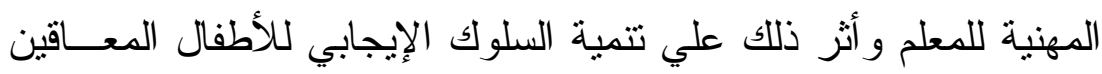
عقليًا.

$$
\text { المراجع }
$$

ا. إسماعيل عبد الفتاح عبد الكافي. (ع ( ب)): سلسلة تعليم وتدريب المعساقين عقليًا ، طا، مركز الإسكندرية للكتاب، القاهرة.

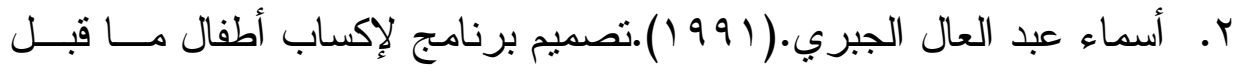
الدرسة مهارة التعاون، رسالة دكتور اه، منشورة، كلية التزبية، جامعة عين شمس.

المجلد السادس




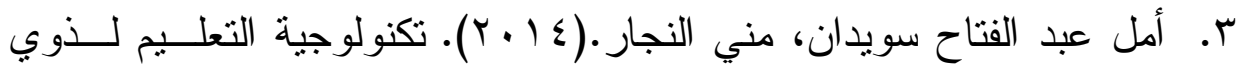
الحاجات الخاصة ، طع، دار الفكر ، الأردن.

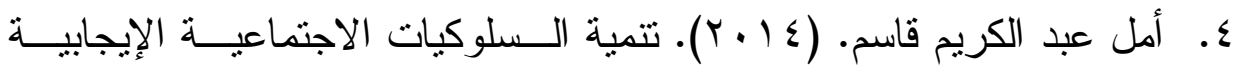

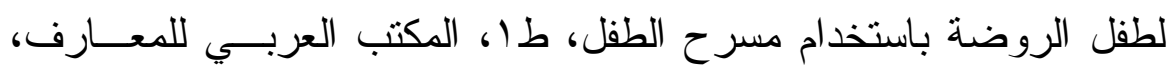
القاهرة.

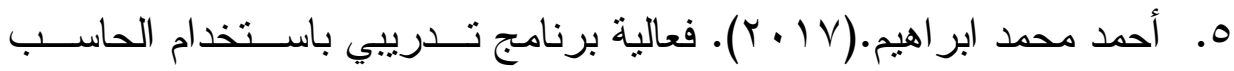

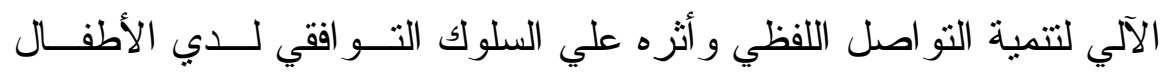

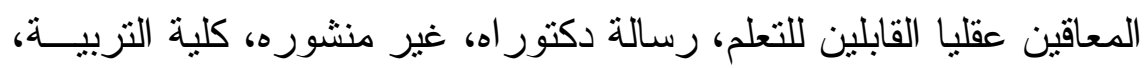
جامعة المنصورة.

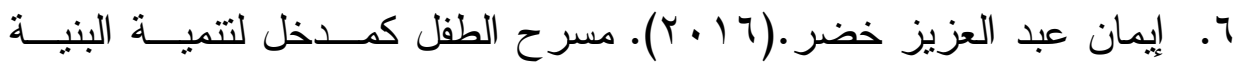

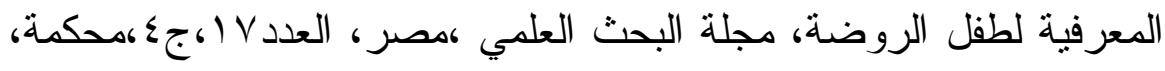
.rT-1

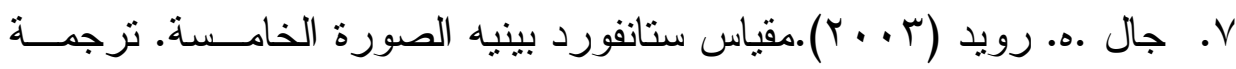
صفوت فرج ،مكتبة الأنجلو المصرية.

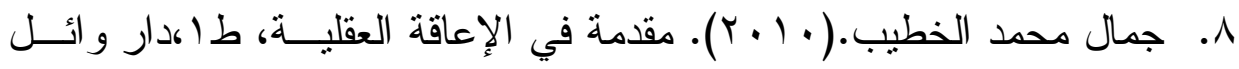

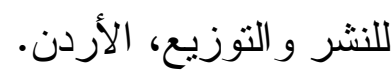

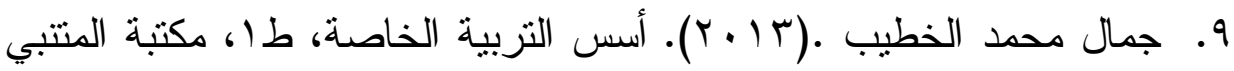
للنشر و التوزيع، الدمام، المملكة العربية السعودية.

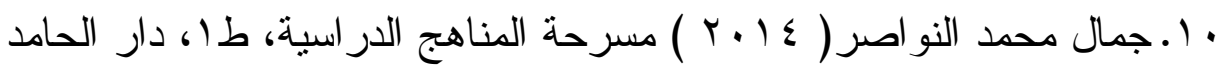
للنشر، عمان،.

المجلد السادس




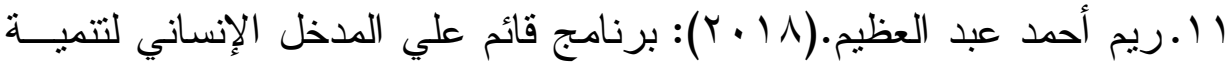
التعبير الثفوي وخفض قلق التحدث لدي تلاميذ المرحلة الابتدائية المعاقين

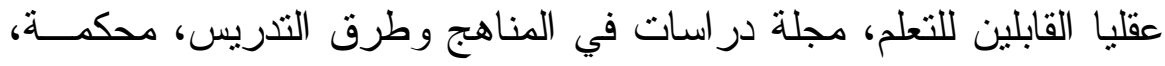
العدد آT ،كلية النزبية، جامعة عين شمس. Y ا. روحية محمد عبد الباسط(0 + ب):الدور الفعال الذي يقدمه مسرح العر ائس

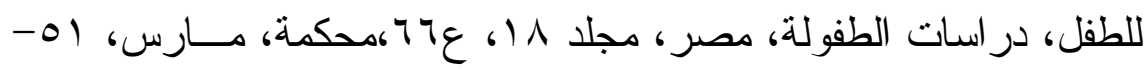
00

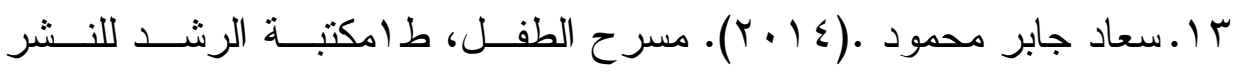

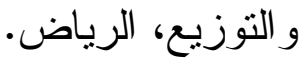

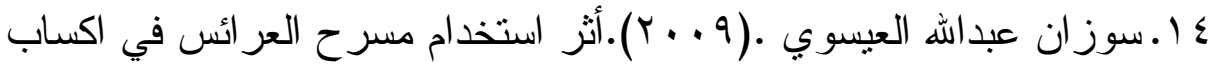

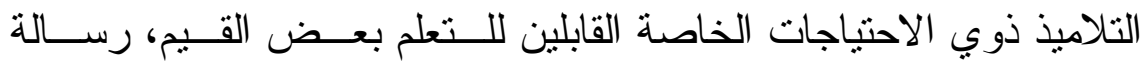
دكتور اه، غير منشورة، معهد در اسات الطفولة، جامعة عين شمس. 10.عادل محمد عبداله .(11 + r). مقدمة في التزبية الخاصة، طا، دار الرشاد للطبع، القاهرة.

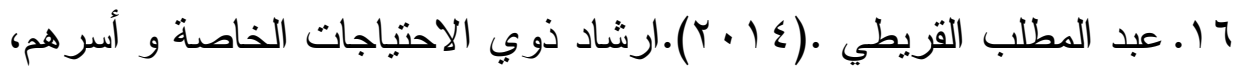
طا، عالم الكتب للنشر و الطباعة، القاهرة.

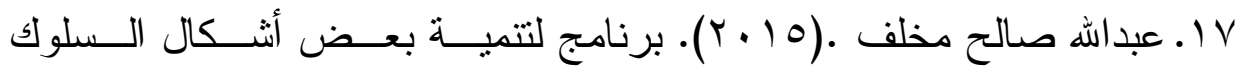

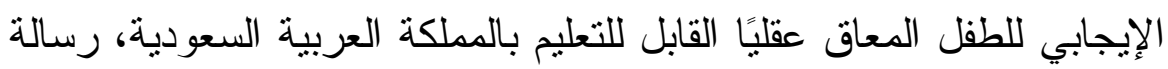
دكتور اه، غير منشورة، معهد الدراسات و البحوث التزبوية، جامعة القاهرة.

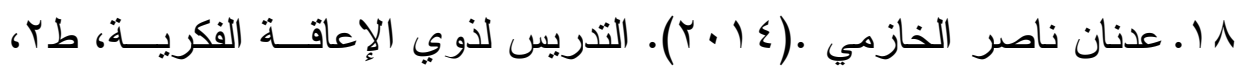
دار المسيرة للنشر و التوزيع، عمان، الأردن. 


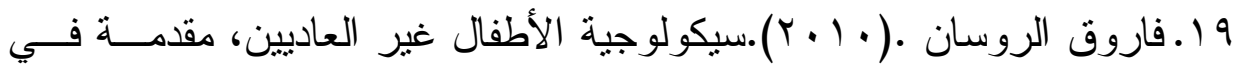
الثزبية الخاصة، طم، دار الفكر للنشر و التوزيع، الأردن.

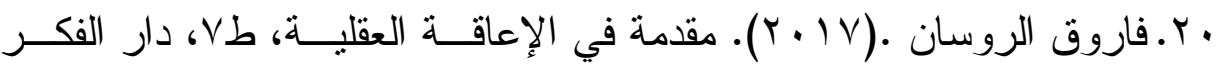

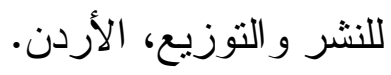

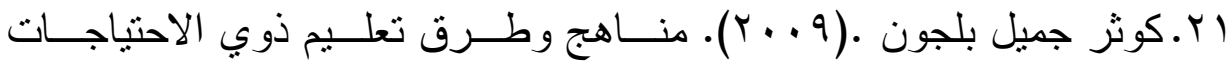
الخاصة، طا ا، مكتبة البركة للطباعة، السعودية.

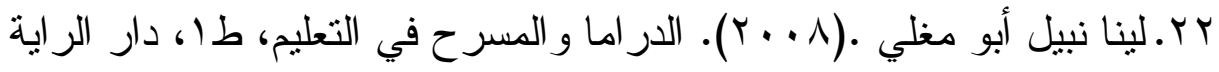

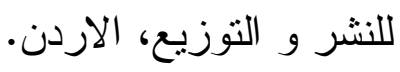

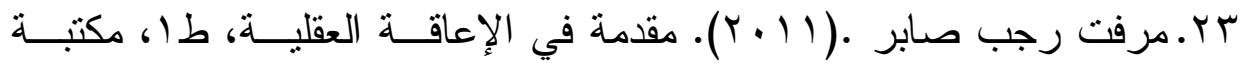
المتنبي، الدمام ، السعودية.

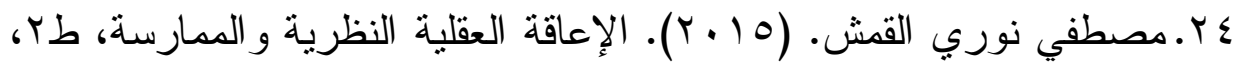
دار المسيرة للنشر و الطباعة، الأردن.

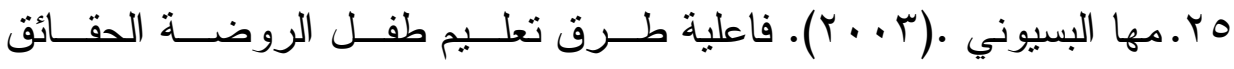

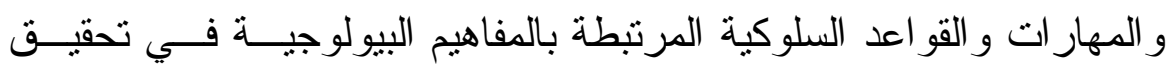

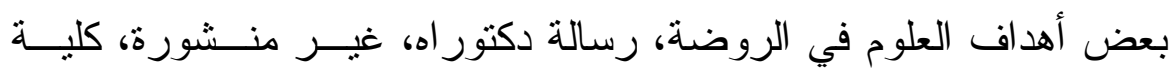
البنات، جامعة عين شمس.

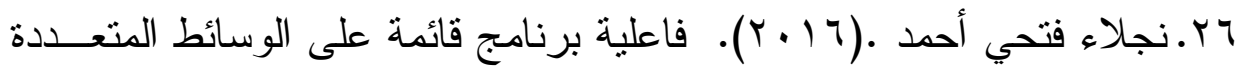

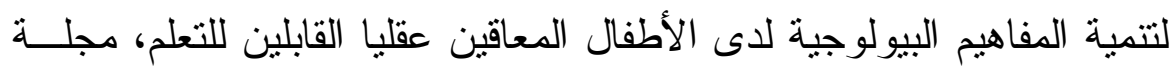

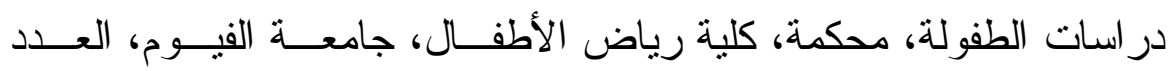
الر ابع.

r المجلد السادس




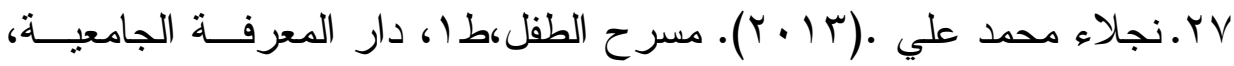

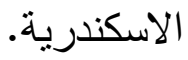

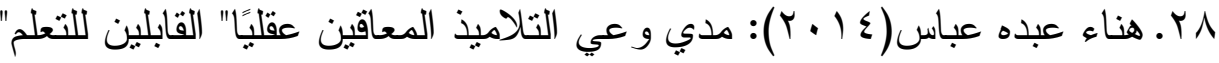

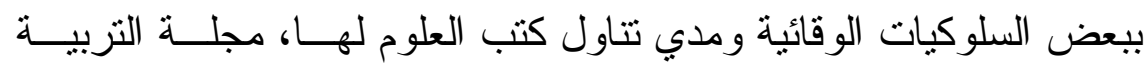

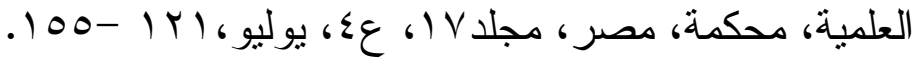

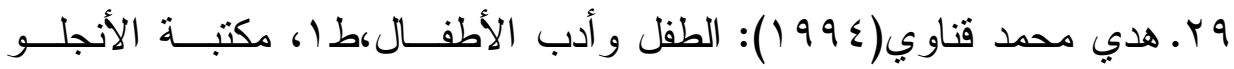

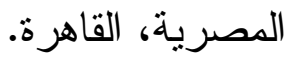

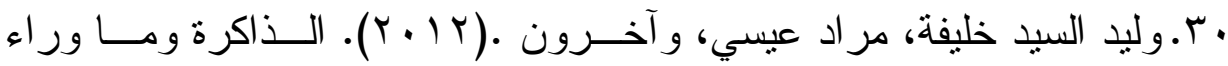
الذاكرة لدي المتخلفين عقليًا في ضوء علم النفس المعرفي، طا، دار الوفاء

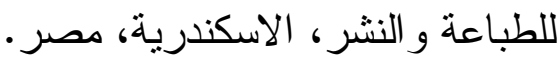

31.American Psychiatric Assoiation.,(2013). Diagnostic and statistical manual of mental disorders(5thed) Arlington, VA: American Psychiatric Publishing.

32.Sedat Maden_( 2010 ) : Child Theatre Thought turkey and native theatre, Journal of New World Sciences Academy, V: 5- N: 3, Article Number. 3C0045

33. Schuchardt, K, Gebhardt,M, C(2010): Working Memory Function in Children with Different Degrees of Intellectual Disability Journal of Intellectual Disability Research, v54 n4 p346-353 Apr.

r.19 العدد الأول : يوليو

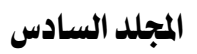


34.Sideridis,G.D.(2009).Assessing Cognitive interference using the Emotional Stroop Task in Student With and without attention problems. European Journal of psychological Assessment,25(2),99-106.

35.Tremblay ,Karine N.Richer ,Louis. Lachance. Lise Cote,Alain (2010) Psychopathological Marinfestations of children with intellectual Disabilities According to Their cognitive and Adaptive Behavior Profile Research in Dvelopmental Disabilities :A Multidis ciplinary Journal .v3 ,n1,p5

36.Van Ingen,D; Moorea, L; Zaja, R\& Rojahn, J.(2010).the Behovior Problems Inventory (BPI-01) inCommunity Based Adults with Intellectual Disabilities: Reliability and Concurrent Validity vis-à-vis the Inventory for Client and Agency Planning (ICAP). Research in Developmental Disabilities: AMultidisciplmary Journal,31,(1),97-107.

37.Kaval.(2009) Atime to Define: Making the specific learning Disabilitiy, facutty publiations and presentations Liberty university, paper 108. 
38.McDermott,SDurkin,M.,Schuef,N.,\&stein,Z.(2009).Epidem iology andetiology of mental retardation.

39. InJ.Jacbson,J.Muliclk\&J.Rojahn (Eds) Handbook of Intellectual and developmental disabilities (pp-340).Newyork: Springer.

40.Putnam ,J.W \&. Johson ,R.T(2008): Collaborative skill instruction for promoting positive interaction between mentally handicapped \& non handicapped children. 